\title{
Ethylene oxide: an assessment of the epidemiological evidence on carcinogenicity
}

\author{
Roy E Shore, Martin J Gardner, Brian Pannett
}

\begin{abstract}
Mortality from cancer among workers exposed to ethylene oxide (EtO) has been studied in 10 distinct cohorts that include about 29800 workers and 2540 deaths. This paper presents a review and meta-analysis of these studies, primarily for leukaemia, nonHodgkin's lymphoma, stomach cancer, pancreatic cancer, and cancer of the brain and nervous system. The magnitude and consistency of the standardised mortality ratios (SMRs) were evaluated for the individual and combined studies, as well as trends by intensity or frequency of exposure, by duration of exposure, and by latency (time since first exposure). Exposures to other workplace chemicals were examined as possible confounder variables. Three small studies by Hogstedt initially suggested an association between EtO and leukaemia, but in seven subsequent studies the SMRs for leukaemia have been much lower. For the combined studies the SMR $=1.06(95 \%$ confidence interval $(95 \%$ CI) 0.73-1.48). There was a slight suggestion of a trend by duration of exposure $(p=0 \cdot 19)$ and a suggested increase with longer latency $(p=0.07)$, but there was no overall trend in risk of leukaemia by intensity or frequency of exposure; nor did a cumulative exposure analysis in the largest study indicate a quantitative association. There was also an indication that in two studies with increased risks the workers had been exposed to other potential carcinogens. For non-Hodgkin's
\end{abstract}

Department of Environmental Medicine, New York University Medical School, USA

R E Shore

Medical Research Council, Environmental Epidemiology Unit, University of Southampton, UK M J Gardner, B Pannett

Appreciation: We regret the untimely death of Dr Gardner as this paper was nearing completion. We are grateful for his guidance and efforts. lymphoma there was a suggestive risk overall (SMR $=1 \cdot 35$, 95\% CI 0.93-1.90). Breakdowns by exposure intensity or frequency, exposure duration, or latency did not indicate an association, but a positive trend by cumulative exposure $(p=0.05)$ was seen in the largest study. There was a suggested increase in the overall SMR for stomach cancer $(S M R=1 \cdot 28$, 95\% CI 0.98-1.65 (CI 0.73-2.26 when heterogeneity among the risk estimates was taken into account)), but analyses by intensity or duration of exposure or cumulative exposure did not support a causal association for stomach cancer. The overall SMRs and exposureresponse analyses did not indicate a risk from EtO for pancreatic cancer $(S M R=0.98)$, brain and nervous system cancer (SMR = $0 \cdot 89$ ), or total cancer $(S M R=0.94)$. Although the current data do not provide consistent and convincing evidence that EtO causes leukaemia or non-Hodgkin's lymphoma, the issues are not resolved and await further studies of exposed populations.

(British fournal of Industrial Medicine 1993;50:971-997)

Annual production of ethylene oxide (EtO) is nearly three million tonnes in the United States and over 5.5 million tonnes worldwide. ${ }^{12}$ About $60 \%$ is used to produce ethylene glycol, $12 \%$ to produce non-ionic surfactants, and lesser percentages to produce glycol ethers, ethanolamines, and other chemicals. ${ }^{3}$ Ethylene oxide has also been used as a fumigant and sterilant of medical products, foodstuffs, and a variety of other products. In 1983, OSHA estimated that 80000 United States workers were directly exposed to EtO, and that another 144000 may have been incidentally exposed. ${ }^{3}$ In 1984 the United States OSHA established a standard which reduced the limit on eighthour time-weighted average exposure from $50 \mathrm{ppm}$ to $1 \mathrm{ppm}$ with a 10 minute ceiling of $5 \mathrm{ppm}$.

Ethylene oxide is a direct acting epoxide and alkylating agent which is mutagenic in mammalian cell systems. It has been shown to induce sister 
chromatid exchanges and chromosomal aberrations in lymphocytes of exposed workers and micronucleation in bone marrow. Animal studies of the carcinogenicity of EtO have found excess tumours of the forestomach and brain, and excess peritoneal mesothelioma and mononuclear cell leukaemia. ${ }^{3}$

Since 1979, when the first epidemiological study of cancer mortality among EtO exposed workers was published, ${ }^{4}$ the literature has expanded rapidly and currently includes published studies of 10 distinct exposed worker cohorts. ${ }^{5-18}$ Studies have been reported from Sweden, Germany, Italy, the US, and Great Britain, and include workers involved in the production of EtO and in its use as a chemical intermediate or a sterilising agent.

Health endpoints that have been pointed to in various human or animal studies as possibly associated with EtO exposure have been examined. Both animal and human studies have suggested leukaemia, other haematopoietic cancers, and stomach cancer as sites, an animal study suggested brain cancer, and human studies suggested pancreatic cancer. We have also evaluated total cancers, circulatory disease, and total mortality as endpoints.

This report presents an overview of the epidemiological studies and estimates the risk for the mentioned diseases based on meta-analyses of the combined data. Where possible, the separate and combined studies were examined for trends in risk by duration of exposure, intensity and frequency of exposure, and latency period. By combining the information from the various studies, meta-analysis potentially yields increased statistical power for detecting risks and increased precision in estimating their magnitude, although meta-analyses should be interpreted cautiously, especially when the results of various studies are divergent.

\section{Review of the epidemiological studies}

A descriptive summary of each study is given, along ? with a critique. Table 1 summarises the number of $\vec{F}$ exposed workers, duration of exposure and length of follow up for each study. Table 2 summarises information on EtO exposure levels for each study, and table 3 provides information on other chemicals to which the workers may have been exposed.

\section{STUDY 1: HOGSTEDT NO 1; SWEDISH STUDY OF STERILANT WORKERS}

Hogstedt $e t a l^{4}$ published the first human study of $\vec{\omega}$ cancer occurrence in EtO exposed workers in 1979. The factory had been using EtO since 1968 for sterilising hospital equipment. A total of 77 women had worked in a hall where the non-airtight

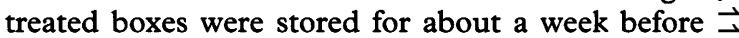
shipment, and another 163 worked in nearby rooms and passed through this hall periodically. EtO air measurements made in the hallway in 1977 엉 showed values from 2 to $70 \mathrm{ppm}$; the estimated time-weighted average exposure was 20 (SD 10) $\mathrm{ppm}$. More detail on exposure is given in Table 2 . The cases were exposed for four to 10 years.

The safety committee at the plant noticed that three cases of "leukaemia" had occurred among workers and reported it to the Swedish OSHA io \& 1977, which prompted this study. One case of "leukaemia" proved to be Waldenstromes. macroglobulinaemia, which is not classified as malignancy, ${ }^{19}$ whereas the other two were myeloid leukaemias. It was subsequently reported that 0.09 leukaemias, or 0.16 total haematopoietic $\stackrel{D}{2}$ malignancies, would have been expected for this $\overrightarrow{\vec{B}}$ cohort during 1968-77, based on Swedish national rates. ${ }^{6}$

Another report of this study provided an update

Table 1 Number of workers exposed to EtO, duration of exposure, and duration of follow up for each study

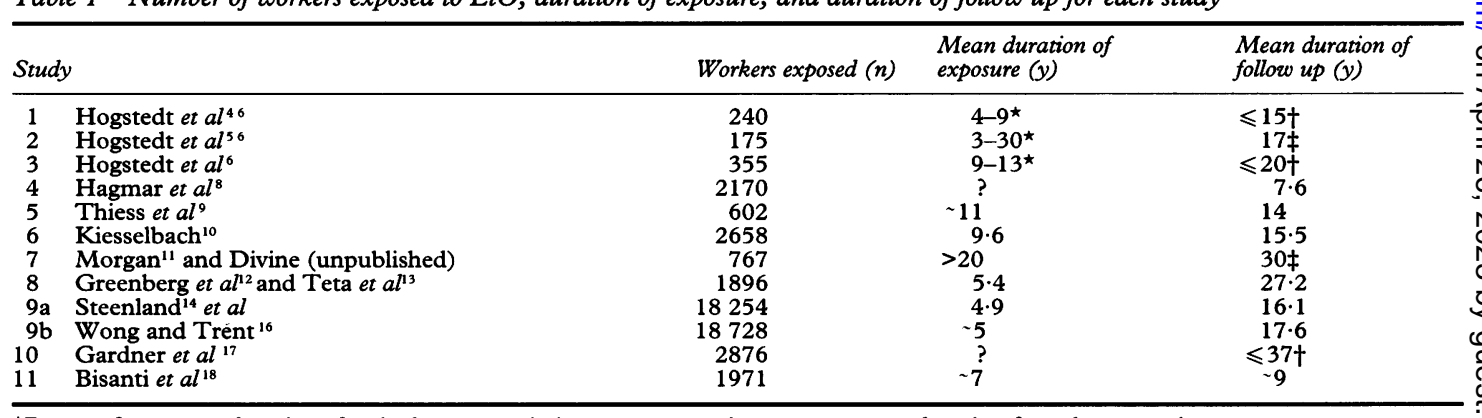

^Range of exposure durations for the haematopoietic cancer cases. Average exposure duration for cohort not given.

$t \leqslant$ indicates that only the maximum follow up period is known. Some or many workers may have had a shorter follow up than this.

$\ddagger$ Mean length of follow up was not given. Mortality was documented only for the follow up period indicated, but exposure for some workers began up to 20 years prior to the follow up period in Hogstedt's study, or up to seven years earlier in the study of Morgan et al ${ }^{11}$ and Divine. 
Table 2 Exposure to ethylene oxide and the type of work

\begin{tabular}{|c|c|c|c|c|}
\hline \multicolumn{2}{|c|}{ Study } & \multirow{2}{*}{$\begin{array}{l}\text { Average exposures (ppm) } \\
\text { by time period } \\
\begin{array}{l}1968-77: \text { mean } 20(10) \text { in } \\
\text { sterilisation room; } \\
2-70 \text { in storage hall }\end{array}\end{array}$} & \multirow{2}{*}{$\frac{\text { Peak exposures (ppm) }}{330-990}$} & \multirow{2}{*}{$\begin{array}{l}\text { Nature of work } \\
\text { and production process } \\
\text { Sterilisers, packers, workers } \\
\text { in adjacent rooms }\end{array}$} \\
\hline 1 & Hogstedt et al ${ }^{40}$ & & & \\
\hline 2 & Hogstedt et $a l^{57}$ & $\begin{array}{l}\text { 1941-47: - 14; } \\
\text { 1950-63: } 5-27 \\
1964-76:<1-6\end{array}$ & $\begin{array}{l}\text { 1941-63: peaks }>400 ;^{\star} \\
\text { 1940s: used taste test of } \\
\text { EtO reaction product. } \\
\text { 1964+: not given }\end{array}$ & $\begin{array}{l}\text { Production, chlorohydrin } \\
\text { process } 1940-63 ; \dagger \\
\text { EtO used but not produced } \\
\text { thereafter }\end{array}$ \\
\hline 3 & Hogstedt et $a l^{67}$ & $\begin{array}{l}\text { 1963-76: } 1-8 \\
1977-82: 0 \cdot 2-2\end{array}$ & 1963-82: 330-990 & $\begin{array}{l}\text { Production, direct oxidation } \\
\text { process; ethylene glycol } \\
\text { production }\end{array}$ \\
\hline 4 & Hagmar et $a l^{8}$ & $\begin{array}{l}\text { 1964-72: } 40-75 \text { for } \\
\text { sterilisers and packers; } \\
\text { 1973-78: } 1-10 \text {; } \\
\text { 1979-86: }<0 \cdot 2-2\end{array}$ & ? & Steriliser workers \\
\hline 5 & Theiss et $a l^{9}$ & $\begin{array}{l}\text { 1978-80: mostly <5; } \\
<1978: \text { higher }\end{array}$ & $\begin{array}{l}<1978:>400^{\star} \text { and medical } \\
\text { reports of acute symptoms; } \\
1978-80:>100\end{array}$ & $\begin{array}{l}\text { 1928-65: EtO produced by } \\
\text { chlorohydrin process; } \\
\text { 1965-80: direct oxidation } \\
\text { process }\end{array}$ \\
\hline 6 & Kiesselbach et $a l^{10}$ & $\begin{array}{l}\text { 1928-81: qualitative only } \\
\text { ("weak, medium, high") }\end{array}$ & $?$ & $\begin{array}{l}\text { EtO production, methods } \\
\text { unspecified }\end{array}$ \\
\hline 7 & Morgan et $a l^{11}$ & $\begin{array}{l}\text { 1948-76: "well below 50"; } \\
\text { 1977: <10 }\end{array}$ & 1960s: $>400^{\star}$ & $\begin{array}{l}\text { 1948-64: chlorohydrin } \\
\text { process; } \\
\text { 1958-85: Direct oxidation } \\
\text { process }\end{array}$ \\
\hline 8 & $\begin{array}{l}\text { Greenberg et al }{ }^{12} \\
\text { and Teta } e t \text { al }^{13}\end{array}$ & $\begin{array}{l}\text { 1925-39: >14; } \\
\text { 1940-56: } 14 ; \\
\text { 1957-73: } 5-10 \\
1974-88:<1\end{array}$ & $\begin{array}{l}\text { Earlier years: }>400^{\star} \text { and } \\
\text { more than } 100 \text { medical } \\
\text { reports of acute symptoms }\end{array}$ & $\begin{array}{l}\text { 1925-57: production, } \\
\text { chlorohydrin process; } § \\
\text { 1937-71: direct oxidation; } \\
\text { 1972-88: EtO used but not } \\
\text { produced }\end{array}$ \\
\hline 9 & $\begin{array}{l}\text { Steenland et al }{ }^{14} \\
\text { and Wong and Trent }{ }^{16}\end{array}$ & $\begin{array}{l}\text { 1977-85: mean } 4 \cdot 3 \text { for } \\
\text { steriliser operators and } 2 \cdot 0 \\
\text { for others; } \\
1938-76 \text { : estimated as } 16 \\
\text { for steriliser operators and } 5 \\
\text { for others }\end{array}$ & $?$ & $\begin{array}{l}\text { EtO used to sterilise medical } \\
\text { supplies and spices }\end{array}$ \\
\hline 11 & Bisanti et al 18 & 1938-84: unknown & ? & $\begin{array}{l}\text { Chemical workers licensed } \\
\text { to handle EtO }\end{array}$ \\
\hline
\end{tabular}

${ }^{\star}$ Greater than the odour threshold, which is estimated to be about $400 \mathrm{ppm}$.

$\nmid$ Most of the production was in an enclosed building.

fOutdoor reaction system; EtO run on the ground for samples and maintenance.

$\S$ Enclosed building in the early years.

The authors reported that the Italian $\mathrm{TWA}_{8}$ standard for EtO was lowered from $50 \mathrm{ppm}$ to $3 \mathrm{ppm}$ in 1983 and that exposures were known to have sometimes exceeded $50 \mathrm{ppm}$ prior to 1983.

for $1978-82^{6}$ and recorded one additional leukaemia case. Other types of cancer were not reported on. A third report updated the mortality data through 1985 and the incidence data through 1983. ${ }^{7}$ No additional haematopoietic cancers were found, but the augmented number of expected haematopoietic cancers was not reported for the study. (A case of polycythemia vera was found, but this is no longer coded as a malignancy in the 9th revision of the International Classification of Diseases. $)^{20}$

\section{Critique}

Since the first report was based on the initial, informal observation of a cluster of three cases, including these cases in an overall assessment of risk would bias the results. ${ }^{2122}$ The subsequent leukaemia case was included in the overall risk assessment. The observed to expected ratio $(\mathrm{O} / \mathrm{E}=$ $1 / 0.05 ;$ SMR $=20$ ) associated with it is biased upward since an updated expected value was not reported for the latest follow up. There was no reporting of cancer sites other than leukaemia, all haematopoietic cancer and total cancer. The Swedish national cancer registry permitted a high level of ascertainment of cancer incidence and mortality for this cohort. The length of follow up is short in this study (table 1 ).

Having some documentation of the exposure levels in this factory (table 2) is useful, although it is unclear how representative the measurements in 1977 (occurring in the context of the discovery of the cluster) were of the exposures in earlier years. Estimates of individual exposure levels were not provided. There was no systematic analysis of the haematopoietic cancer incidence or mortality by 
Table 3 List of chemicals other than ethylene oxide to which workers may have been exposed, broken down by study

\begin{tabular}{|c|c|c|}
\hline \multicolumn{2}{|c|}{ Study } & \multirow{2}{*}{$\begin{array}{l}\text { Other chemicals or substances to which workers may have been exposed (reported concentrations given when available) } \\
\text { Benzene, methyl formate (1:1 mixture with EtO) }\end{array}$} \\
\hline 1 & Hogstedt et al 46 & \\
\hline 2 & Hogstedt et al & $\begin{array}{l}\text { Bis- }\left(2 \text {-chloroethyl ether }\left(0.05 \mathrm{mg} / \mathrm{m}^{3}\right) \text {, cellulose ethers, chloral, chlorinated acetals, chloroform, DDT, }\right. \\
\text { ethylene }\left(600 \mathrm{mg} / \mathrm{m}^{3}\right) \text {, ethylene chlorohydrin }\left(5 \mathrm{mg} / \mathrm{m}^{3}\right) \text {, ethylene dichloride (dichloroethane) } \\
\left(100 \mathrm{mg} / \mathrm{m}^{3}\right) \text {, ethylene glycol, propylene oxide }(4-11 \mathrm{ppm})\end{array}$ \\
\hline 3 & Hogstedt et $a l^{6}$ & Amines, butylene oxide, ethylene, formaldehyde, propylene(?), propylene oxide, sodium nitrate \\
\hline 4 & Hagmar et $a l^{8}$ & Fluorochlorocarbons, methyl formate (1:1 mixture with EtO) \\
\hline 5 & Thiess et al ${ }^{9}$ & $\begin{array}{l}\text { Aniline, benzene, butylene oxide, cyclohexamine, cyclohexane, dichloropropane, dioxane, epichlor- } \\
\text { hydrin, ethylene chlorohydrin, ethyleneimine, formaldehyde, iso-butyraldehyde, piperazine, propy- } \\
\text { lene, propylene chlorohydrin, propylene oxide }\end{array}$ \\
\hline $\begin{array}{l}6 \\
7\end{array}$ & $\begin{array}{l}\text { Kiesselbach et al }{ }^{10} \\
\text { Morgan et } a l^{11} \text { and }\end{array}$ & 2-Naphthylamine, 4-amino-diphenyl, benzene, ethylene chlorohydrin(?) \\
\hline & Divine (unpublished) & ? \\
\hline 8 & Greenberg et al ${ }^{12}$ & \\
\hline & & $\begin{array}{l}\text { Acetaldehyde, acetonitrile, acrolein, aldehydes, aliphatic and aromatic alcohols, } \\
\text { alkanolamines, allyl chloride, amines, butadiene, benzene, bis-(2-chloroethyl) ether, ethylene dichloride, } \\
\text { diethyl sulphate, dioxane, epichlorhydrin, ethylene, ethylene chlorohydrin, ethylene dichloride, formalde- } \\
\text { hyde, glycol ethers, methylene chloride, propylene chlorohydrin, styrene, toluidine }\end{array}$ \\
\hline 9 & $\begin{array}{l}\text { Steenland et al }{ }^{14} \text { and } \\
\text { Wong and Trent }{ }^{16}\end{array}$ & 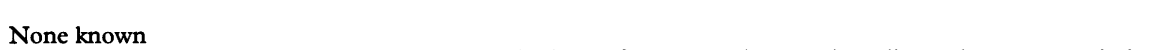 \\
\hline 10 & Gardner et al ${ }^{17}$ & $\begin{array}{l}\text { Aliphatic and aromatic alcohols, amines, anionic surfactants, asbestos, butadiene, benzene, cadmium } \\
\text { oxide, dimethylamine, ethylene, ethylene chlorohydrin, ethylene glycol, formaldehyde, heavy fuel oils, } \\
\text { methanol, methylene chloride, propylene(?), propylene oxide, styrene, tars, white spirit }\end{array}$ \\
\hline 11 & Bisanti et $a l^{18}$ & $\begin{array}{l}\text { Dimethyl sulphate, methylene chloride, carbon disulphide, phosgene, chlorine, alkalic cyanides, sulfur } \\
\text { dioxide, anhydrous ammonia, hydrocyanic acid }\end{array}$ \\
\hline
\end{tabular}

duration of exposure, cumulative exposure (duration $\times$ intensity), nor time since first exposure. These workers apparently did not have exposure to many chemicals in the workplace (table 3 ).

\section{STUDY 2: HOGSTEDT NO 2; SWEDISH STUDY OF EtO PRODUCTION WORKERS}

Hogstedt et al ${ }^{5-7}$ studied workers in 1977 on whom Ehrenberg and Hallstrom ${ }^{23}$ had conducted a haematological investigation at this $\mathrm{EtO}$ production facility in 1960-61. This included 175 men working for a company that had been producing EtO since the early 1940 s, of whom 89 were EtO production workers and 86 were maintenance workers with intermittent EtO exposure.

Ethylene oxide was produced by the chlorohydrin process. The EtO exposure levels for the period 1941-47 were estimated as "probably below" $14 \mathrm{ppm}$, * based on interviews with workers and not measurements, but there were occasional exposures above the odour threshold (which is estimated to be about $400 \mathrm{ppm}^{24}$ ). From about 1950 to 1963 the production of EtO-based compounds increased, and average exposures of 5-27 ppm were estimated, with peaks above the odour threshold. After 1963 EtO was used but not produced, and measurements indicated that exposures were in the range of $0.5-5 \mathrm{ppm}$.

In the latest report, ${ }^{7}$ (to the end of 1985) they had recorded three leukaemias among exposed workers $v 0.43$ expected $(\mathrm{SMR}=7 \cdot 0)$. An excess

\footnotetext{
^For consistency, all values given in $\mathrm{mg} / \mathrm{m}^{3}$ have been converted to $\mathrm{ppm}$, using a conversion of $1 \mathrm{ppm}=1.83 \mathrm{mg} / \mathrm{m}^{3}$.
}

of stomach cancer was also seen $(\mathrm{O} / \mathrm{E}=9 / 1 \cdot 27$; SMR $=7 \cdot 1$ ). These effects were (non-significantly) greater among the full time exposed workers than among the intermittently exposed maintenance workers. They also observed an excess of diseases of the circulatory system, although this excess was similar in the exposed and unexposed groups.

Workers were exposed to a number of chemicals from other processes (table 3) and also were exposed to intermediates used in the production of EtO by the chlorohydrin process, including ethylene chlorohydrin, ethylene dichloride and bis (2chloroethyl) ether.

\section{Critique}

This study cohort consisted of the workers on whom Ehrenberg and Hallstrom ${ }^{23}$ had conducted a haematological screening in 1960-61. It is unclear as to what percentage of the potentially exposed workers were included in this screening or how representative the screened workers were of the entire potential exposed group. The Swedish national cancer and death registries provide a high level of ascertainment of cancer incidence and mortality. The study did not report on brain or pancreatic cancer, evidently because there were no excesses at these sites.

The investigators made an attempt to estimate EtO air concentrations, albeit crudely, for different historical periods. In various reports they provided some information on exposure duration ${ }^{6}$ and latency, ${ }^{5}$ but the numbers were too small to be very informative. A number of other chemicals were present in the work environment (table 3), including some that were unique to this study among the studies reviewed here. 
STUDY 3: HOGSTEDT NO 3; SWEDISH STUDY OF EtO PRODUCTION WORKERS

Hogstedt et $a l^{6}$ first reported on this cohort in 1986. At this factory, EtO was produced by the direct oxidation process. Workers with at least one year of employment numbered 355, including 128 in EtO production, 69 who processed EtO and propylene oxide to make non-ionic surfactants and polyols, and 158 maintenance and technical workers. The first group had exposure almost exclusively to EtO, whereas the last two groups had exposure to multiple chemicals (table 3). Estimated EtO exposure levels are shown in table 2.

One leukaemia occurred among these workers $v$ 0.16 expected. The case, whose diagnosis was chronic myeloid leukaemia, had worked in maintenance and repair. A case of reticulum cell sarcoma was also reported in a later publication. ${ }^{7}$

\section{Critique}

This study contains very limited information, essentially only for leukaemia. Furthermore, the expected values were not updated for the more recent follow up even though the detected deaths were, so the reported $\mathrm{O} / \mathrm{E}$ ratio for leukaemia is biased upward since it does not incorporate the fact that more years of observation have occurred with no additional leukaemias. The follow up time was fairly short (table 1), and the number of cases was too small to permit detailed analyses by duration or intensity of exposure or by cumulative exposure. Furthermore, no estimates of individual EtO exposure were developed. The workers were exposed to other chemicals as well as EtO (table 3 ).

STUDIES 1-3: HOGSTEDT NOS 1, 2, AND 3; REPORT OF COMBINED STUDY RESULTS

Hogstedt $e t a l^{7}$ reported the combined results of their three studies, updated through 1985 for mortality and 1983 for cancer incidence. This joint analysis included 539 men and 170 women, after excluding persons who had been employed at one of the three facilities for less than one year. They reported 33 cancer deaths as compared to 19.8 expected. The excess mortality was in haematopoietic cancers $(\mathrm{O} / \mathrm{E}=9 / 2 \cdot 0)$, mainly leukaemias $(\mathrm{O} / \mathrm{E}$ $=7 / 0 \cdot 8)$, and in stomach cancer $(\mathrm{O} / \mathrm{E}=10 / 1 \cdot 8)$. However, a breakdown by $<10 v 10+$ years of employment did not reveal any trends by duration of employment. They also reported a non-significant excess of mortality due to cerebrovascular disease $(\mathrm{O} / \mathrm{E}=9 / 4.9)$ but none due to ischaemic heart disease $(\mathrm{O} / \mathrm{E}=24 / 24 \cdot 2)$. In examining the incident cases (whether dead or alive), they reported that since the time the initial cluster of haematopoietic cancers was discovered, seven more haematopoietic cancers had been detected $v 2 \cdot 2$ expected (including five leukaemias $v 0.8$ expected).
STUDY 4: HAGMAR; SWEDISH STERILANT WORKERS

Hagmar et al $^{8}$ have followed up $2170 \mathrm{EtO}$ exposed workers from two plants that produced disposable medical equipment. Subjects must have been employed for at least one year during the period of time that EtO was used (1970-85 at plant A or 1964-85 at plant B). Measurements of air concentrations have been made at plant $A$ since 1973 and showed that levels for steriliser workers had dropped from $20-40 \mathrm{ppm}$ in the early 1970 s to $<1 \mathrm{ppm}$ in 1985. Similar decreases over time in exposure levels were seen for other job categories. At plant $B$ the exposures were $50-75 \mathrm{ppm}$ in $1964-66$, but had decreased to $\leqslant 0.5 \mathrm{ppm}$ by 1985. The authors were also able to corroborate exposure levels by measuring $\mathrm{EtO}$ adducts in hemoglobin from exposed workers.

Vital status was determined to the end of 1986, with $100 \%$ follow up. Expected deaths were calculated based on county rates. Cancer incidence was also obtained from the Swedish Cancer Registry. One polycythemia vera and two lymphomas were found, whereas 2.0 haematopoietic cancers were expected. An analysis by cumulative EtO exposure showed that the haematopoietic cancers occurred among those with $\leqslant 1$ ppm-year of exposure, while the 198 workers with $>1$ ppm-year of exposure (with a mean of 25 ppm-years) had no haematopoietic cancers.

\section{Critique}

This is an excellent study in many ways. The exposures were mostly to EtO; the only other exposures were to methyl formate or fluorochlorocarbons (table 3 ). The EtO exposure levels were quantitatively characterised by job category and specific time period, based on some measurements and on "information about major changes in production methods and environmental control as well as subjective memories and fitted time trends." 8 Furthermore, biological dosimetry using haemoglobin adducts was conducted to corroborate the exposure estimates. Integral exposure (in terms of ppm-years) was calculated for individual workers and used in the analysis.

The limitations of the study were mainly intrinsic to the cohort under study. The follow up period was short, and exposure levels were apparently low for most workers, since fewer than 200 workers had more than 1 ppm-year of cumulative exposure.

STUDY 5: THIESS; STUDY OF PRODUCTION WORKERS AT A GERMAN COMPANY

In 1982 Thiess et al $^{9}$ published a study of 602 workers who had been employed in nine plants where EtO and propylene oxide were produced or processed. Ethylene oxide was first produced in 
1928 and propylene oxide in 1959. Ethylene oxide was produced from ethylene chlorohydrin until 1965 , when the direct oxidation process was introduced. Between 1978 and 1980 several dozen EtO air samples were obtained. Most of them were below $4 \mathrm{ppm}$, but spot samples ranged up to $100-300$ $\mathrm{ppm}$. Interviews with older employees indicated that workplace concentrations were higher in the past, including times when workers could smell the $\mathrm{EtO}$ and when workers were treated for intoxication. Workers in the EtO production areas were exposed to a number of other chemicals as well, which are listed in table 3.

The cohort was defined as all persons who had worked for at least six months in an area of EtO or propylene oxide production. Follow up, which averaged 14 years, was successful for $97.6 \%$ of the workers. The mortality experience was compared with national and regional rates, as well as with a cohort of styrene plant employees. Mortality experience was evaluated by exposure duration and latency.

The deaths included four stomach cancers, one myeloid leukaemia, one lymphosarcoma, and one brain tumour. A breakdown by length of exposure did not reveal any obvious associations.

\section{Critique}

This is a well conducted study. The presentation of results was good, with breakdowns by duration of exposure and a 10 year induction period. The follow up period was relatively long (table 1). The main limitations were three: the numbers of subjects and deaths were too small to be very informative; there was no historical quantitative information on exposure levels and, hence, no analysis by cumulative exposure; and the workers were exposed to a number of other chemicals besides EtO. There was no indication as to what percentages had worked with EtO, propylene oxide, or both. There was no analysis of mortality according to whether the workers had worked with the chlorohydrin process or only with the direct oxidation process.

\section{STUDY 6: KIESSELBACH; GERMAN MULTICOMPANY} STUDY OF ETO PRODUCTION WORKERS

Kiesselbach et al ${ }^{10}$ have studied 2658 men from six chemical companies who were exposed to EtO for at least one year between 1928 and 1981. This study apparently includes the eligible workers and deaths from the study by Thiess $e t$ al, ${ }^{9}$ but updates the Thiess study for an additional 1.5 years.

Exposures to workers ranged from one to 42 years, with a median of $9 \cdot 6$ years. The companies attempted to characterise types of jobs according to probable exposure level, using the categories weak, medium, and strong. Exposure levels could be categorised for about two thirds of the workers.
Vital status was ascertained for $97 \cdot 6 \%$ of the cohort. The median length of follow up was 15.5 years. Neither leukaemias $(\mathrm{O} / \mathrm{E}=2 / 2.35)$ nor total haematopoietic cancers $(\mathrm{O} / \mathrm{E}=5 / 4.99)$ were in excess. When the cancer data were broken down by exposure intensity, duration of exposure or latency, there were no material trends by these factors.

\section{Critique}

As in virtually all the other studies, the small number of haematopoietic cancers limited the inferences that could be drawn. No information was presented for brain cancers. An attempt was made to analyse by duration and intensity of exposure, but not by cumulative exposure. Unfortunately, no quantitative values were associated with the exposure-intensity categories, nor was there even any indication that the exposure categories corresponded to similar intensities at different plants or over different time periods. The rather short list of other potential chemical exposures (table 3 ) is probably selective and incomplete.

STUDY 7: MORGAN/DIVINE; STUDY OF EtO PRODUCTION WORKERS IN TEXAS, USA Morgan et al ${ }^{11}$ followed 767 men at an EtO proo duction plant through 1977. Although EtO pro duction had begun in 1948, the cohort consisted of all those working there in 1955-77 who had poten tial EtO exposure and who had been employed at the plant for at least five years. The workers at this plant tended to have long duration of employmen ( $55 \%$ employed for $\geqslant 20$ years).

In 1977 measurements of EtO in the production area were "less than $10 \mathrm{ppm}$." The reaction system and operations were outdoors. Between 1948 and 1964 EtO was manufactured by the chlorohydrin process which used ethylene chlorohydrin. Units to produce EtO by direct oxidation were installed in 1958, 1963, and 1968. Morgan et al ${ }^{11}$ observed non-significant excesses of brain cancer $(\mathrm{O} / \mathrm{E}=$ $2 / 0 \cdot 70)$, pancreatic cancer $(\mathrm{O} / \mathrm{E}=3 / 0 \cdot 80)$, and Hodgkin's disease $(\mathrm{O} / \mathrm{E}=2 / 0.35)$ but a deficit of leukaemia $(\mathrm{O} / \mathrm{E}=0 / 0 \cdot 70)$.

Divine (unpublished observations, presented at the American Conference of Occupational Medicine Meeting, May 1990, Houston, Texas) extended the study through 1985 and achieved a $99 \cdot 7 \%$ follow up rate. The O/E ratio for brain can cer was $3 / 1 \cdot 1$, which was a non-significant elevation. There were no deaths due to leukaemia $(1 \cdot 1$ expected) nor to stomach cancer. The $\mathrm{O} / \mathrm{E}$ for all haematopoietic cancers was $3 / 3 \cdot 0$; all three of the haematopoietic cancers were Hodgkin's disease. The analyses by duration of employment for various cancer sites showed no apparent gradients of risk. Analyses by type of work (production, mainte- 
nance, or quality control laboratory) did not show any particular clustering of cancer deaths.

\section{Critique}

Although many studies use a minimum employment period of a few months or a year as a criterion for entry into the cohort, this study used five years. A long entry criterion such as this raises the possibility that some workers with the most intense exposure may have been excluded from the cohort. ${ }^{25}$ The small number of cancers of specific types also limits the study. The reported EtO measurements were all performed in 1977, which may not have been representative of earlier years. The more recent follow up by Divine had an excellent mortality ascertainment rate, and the follow up period was among the longest of the various studies (table 1), but the temporal analyses were limited because they were based on the duration and time of employment rather than of exposure.

\section{STUDY 8: GREENBERG/TETA; STUDY OF EtO}

PRODUCTION WORKERS IN WEST VIRGINIA, USA

Greenberg et al ${ }^{12}$ reported on a cohort of male workers at two plants which produced and used EtO. This study has been updated an additional 10 years, to the end of 1988 , by Teta et al. ${ }^{13}$ Ethylene oxide production at the plants began in 1925 and 1948. The study population consisted of the 2174 workers ever employed between 1940 and 1978 in EtO areas of the plants, and 26965 workers in the same time period who had not worked in departments with EtO exposure. Production of EtO by the chlorohydrin method began in 1925 and was phased out in 1957, while production by direct oxidation began in 1937 and continued until 1971 . Ethylene oxide continued to be used at the plants after 1971 in producing EtO derivatives.

The EtO production was conducted in enclosed buildings for a number of years and production rates were high (for example, about $113000 \mathrm{~kg} / \mathrm{day}$ in 1946). Substantial air monitoring was not conducted at these plants until 1976 (when EtO production had already ceased), although air monitoring had been conducted at a similar direct oxidation plant in the early 1960 s. $^{26}$ From 1940 to 1957, EtO exposures were probably comparable with those estimated by Hogstedt $e t a l^{5}$ in a similar chlorohydrin based EtO production unit with levels of about $14 \mathrm{ppm}$ and frequent peaks of several hundred ppm (see table 2). From 1925 to 1939 the exposures were probably higher yet, and the medical department had numerous reports of nausea, dizziness, and vomiting associated with EtO exposures. ${ }^{12}$ These effects are reported to occur at EtO exposure levels of several hundred ppm..$^{24}$ Exposure levels in more recent years are shown in table 2.

The exposed group had an average of 5.4 years of exposure and an average follow up time of 27 years (table 1). Vital status was ascertained for $99 \%$ of the workers in the latest follow up, and $99 \%$ of the death certificates were obtained. ${ }^{13}$ The initial report of this study ${ }^{12}$ showed two suggestive elevations in risk: leukaemia $(\mathrm{O} / \mathrm{E}=7 / 3.02)$ and pancreatic cancer $(\mathrm{O} / \mathrm{E}=7 / 4 \cdot 09)$. However, four of the seven leukaemias and six of the seven pancreatic cancers, occurred among the 278 workers in a department which produced ethylene chlorohydrin and propylene chlorohydrin, but in which there was no EtO production and only occasional EtO use. Hence, exposure to EtO was low and infrequent in this department, so it is suspected that chemicals other than EtO produced the excesses. ${ }^{12} 27$

In the second follow up by Teta et al ${ }^{13}$ the men who had worked in this ethylene chlorohydrin department were removed from the study. For the remaining cohort, the $S M R$ s for leukaemia $(\mathrm{O} / \mathrm{E}=$ $5 / 4 \cdot 70)$ or all haematopoietic cancers $(\mathrm{O} / \mathrm{E}=$ $7 / 11 \cdot 82$ ) were not raised. The SMR for pancreatic cancer was less than one, but those for brain and nervous system cancer $(\mathrm{O} / \mathrm{E}=6 / 4 \cdot 00)$ and stomach cancer $(\mathrm{O} / \mathrm{E}=8 / 5 \cdot 00)$ were non-significantly increased. Although quantitative estimates of individual exposure levels were not derived, job-department combinations were assigned to low, medium, or high exposure categories. Workers who had spent at least two years in the high EtO exposure category showed no excess cancer. The stomach and brain cancers occurred mostly among those with low or medium exposure.

\section{Critique}

This cohort was carefully defined, and the follow up rate was high. The length of follow up was among the longest in any study (table 1). Although most measurements of $\mathrm{EtO}$ air concentrations were made after the mid-1970s, some early measurements were made in a sister plant in the period 1955-64. ${ }^{26}$ In the early days, exposure levels were high, so this study has a substantial range of exposure levels. A limitation of the study was lack of quantitative estimates of individual exposure levels. The workers had exposures to a variety of other chemicals (see table 3) as well. The ethylene chlorohydrin department was identified as an area in which EtO exposure was infrequent and low, but in which there was apparently some other chemical that was causing a perturbation in leukaemia and pancreatic cancer mortality.

STUDY 9a: STEENLAND/STAYNER; USA ETO STERILANT WORKERS

Steenland et $a l^{14}$ have ascertained the mortality experience of 18254 workers at 14 plants producing sterilised medical supplies or spices, who were 
followed for an average of 16 years. Job titles were used to define exposure categories. Salaried workers were generally excluded because their work histories had insufficient detail to determine where they had worked. The cohort was $55 \%$ female and $21 \%$ non-white. Vital status was determined for $95.5 \%$ of the cohort. Stayner et al ${ }^{1528}$ subsequently conducted a detailed exposure-response assessment based on individual estimates of cumulative exposure (intensity $\times$ duration).

The workers averaged 4.9 years of EtO exposure. Most companies had air sampling data from 1978 onward, but little was available before that date. Based on $>600 \mathrm{EtO}$ air samples for steriliser operators between 1976 and 1985, the average TWA $_{8}$ exposure level was $4.3 \mathrm{ppm}$, and for other exposed workers it was $2.0 \mathrm{ppm}$. About $86 \%$ of the workers had exposures before 1978, when the exposure levels were believed to have been higher.

There were no significant excesses of cancer mortality in the cohort, except for a suggestive increase in kidney cancer $(\mathrm{O} / \mathrm{E}=13 / 7 \cdot 2)$, a type of cancer for which there was no a priori hypothesis because an excess had not been seen in previous studies. An exposure-response analysis, however, did not confirm an association between EtO and kidney cancer. ${ }^{15}$ The SMRs for haematopoietic cancers were increased for men $(\mathrm{O} / \mathrm{E}=27 / 17 \cdot 4)$ but depressed for women $(\mathrm{O} / \mathrm{E}=9 / 16 \cdot 7)$. A breakdown of deaths by job category showed that the steriliser operators, who were thought to have the greatest EtO exposures, had the highest SMRs for leukaemia and all haematopoietic cancers, but neither the elevations in SMRs nor the differences between subgroups were significant. Analyses by duration of exposure did not reveal significant increasing trends for any type of cancer, but the analyses by cumulative exposure (duration $x$ intensity) indicated exposure-response relations for non-Hodgkin's lymphoma.

When the data were broken down by latency, (length of time since first EtO exposure) there was a significantly increasing trend for all haematopoietic cancers, with a trend of similar magnitude for leukaemia. When the subgroup with $>$ seven years of exposure and $>20$ years since first exposure was examined, the SMR for all haematopoietic cancers was $1 \cdot 88$.

\section{Critique}

This is a well executed study that eclipsed all the previous studies in size but has several intrinsic limitations. Prior to 1978 when exposure levels are thought to have been higher, there was essentially no measured exposure information, although there was after 1978. The average follow up period was fairly short, such that only $8 \%$ of the workers had attained $>20$ years since first exposure. Analyses were presented by duration of exposure and latency. Only this study and the much smaller study by Hagmar et $a l^{8}$ have conducted analyses by cumulative exposure, which is preferable to separate analyses by duration or intensity of exposure.

\section{STUDY 9b: WONG; USA ETO STERILANT WORKERS} Wong and Trent ${ }^{16}$ have conducted a further study of essentially the same population that Steenland $e t$ $a l^{14}$ studied. The follow up was for one year past the closing date of Steenland's study, so the observed and expected numbers of diseases were somewhat greater in the study of Wong and Trent. ${ }^{16}$ The study population consisted of 18728 persons who were potentially exposed to EtO for at least 90 days in the industry, including 8709 men and 10019 women. About $80 \%$ were hired between 1960 and 1979; about half worked for five or more years and $30 \%$ for 10 or more years. The average length of follow up was $17 \cdot 6$ years (table 1 ).

About $20 \%$ of the workers were steriliser operators. Their $\mathrm{TWA}_{8}$ EtO exposure was estimated to be $4-5 \mathrm{ppm}$ after 1978 and $16 \mathrm{ppm}$ before that time. For the other workers, the estimated TWA $_{8}$ exposure levels were estimated to be $2 \mathrm{ppm}$ after 1978 and $5 \mathrm{ppm}$ before 1978. The average dura- 8 tion of exposure was five years.

There was no significant excess of any type of cancer. Analyses by duration of employment or by latency time since first employment did not reveal any significant positive trends. Analyses of specific subtypes of leukaemia did not identify any excess risk. However, their analyses agreed with those of Steenland $e t a^{14}$ in finding an excess of nonHodgkin's lymphoma among men, but a deficit of similar magnitude among women.

\section{Critique}

This study is slightly larger than the corresponding study by Steenland $e t a l^{14}$ by virtue of its additional year of observation. The adequacy of mortality follow up is not well documented in the study, although it is probably reasonably good, since about $90 \%$ of the subjects had vital status ascertainment during the time when the Social Security Administration was providing more detailed vital status information. However, the assumption was made that all workers not identified as dead were alive at the study closing date; to the degree that this assumption is not true, it would artificially depress the SMRs.

Although average exposure levels were estimated for types of work and time periods, individual estimates of exposure intensity and frequency were not assigned. The temporal analyses were limited in that they were based on the duration and time of employment rather than of exposure. 
STUDY 10: GARDNER; BRITISH STUDY OF EtO PRODUCTION AND STERILANT WORKERS

Gardner et $a l^{17}$ followed up 2876 men and women from four companies that produced or used EtO and eight hospitals that used EtO sterilisers. Three companies began producing EtO in 1950, 1955 and 1960 respectively, and a fourth began using it in 1959. Two companies produced EtO using the chlorohydrin process for 10-15 years before shifting to the direct oxidation process, while the third producer used only direct oxidation. The first date of EtO use at the eight hospitals ranged from 1962 to 1972. EtO measurements were not available before 1977. The TWAs for almost all jobs since then have been $<5$ ppm, although average exposures were believed to have been higher in earlier years and peak exposures sometimes exceeded the odour threshold (of about $400 \mathrm{ppm}$ ). There was relatively little exposure of the hospital workers to other potentially carcinogenic chemicals, but the chemical workers may have had exposure to a variety of other compounds (see table 3).

The vital status of workers was $>98 \%$ complete. Insufficient information was available to assign exposure values to workers, but their exposure status was classified as definite, possible, or unknown. Tabulations were examined by those categories and by duration of definite exposure and years since first definite exposure. A small excess of leukaemia mortality was observed among the chemical workers $(\mathrm{O} / \mathrm{E}=3 / 1 \cdot 33)$ and a deficit among the hospital workers $(\mathrm{O} / \mathrm{E}=0 / 0 \cdot 76)$, but neither was significant. An analysis of leukaemia by duration of exposure showed no trend.

\section{Critique}

This epidemiological study was of good quality, with a high follow up rate, but the average duration of follow up was not reported. One limitation of the study was the relatively small sample size. While the investigators were able to sort out the degree or frequency of exposure into definite or possible or unknown, no quantitative exposure information was available prior to about 1977 , so exposure levels were not estimated for individual workers. Although some of the production facilities had used the chlorohydrin process in the earlier days, the data were not broken out by chlorohydrin $v$ direct oxidation process exposure. The production workers had exposure to numerous chemicals (table 3). No information was presented on brain cancer.

\section{STUDY 11: BISANTI; ITALIAN STUDY OF WORKERS} LICENCED TO USE ETO

A licence is required in Italy to handle certain toxic gases. Bisanti et al ${ }^{18}$ have studied chemical workers licensed to handle EtO during the period 1938-84 in two regions of northern Italy. The study included 1971 male chemical workers: 637 licensed to handle only EtO, and 1334 licensed to handle EtO plus other chemicals. Mortality follow up was $99.2 \%$ complete. The mean length of follow up was $9 \cdot 8$ years.

They had no information on worker exposure levels at individual facilities. They reported that in 1983 the Italian TWA $\mathrm{TW}_{8}$ standard for EtO was lowered from $50 \mathrm{ppm}$ to $3 \mathrm{ppm}$, and that, prior to 1983, exposures were known to have sometimes exceeded $50 \mathrm{ppm}$. All the haematopoietic cancer cases were first licensed to handle EtO prior to 1979. They also indicated that it is likely that a proportion of the workers first obtained a licence for EtO only after they had worked with it for some while, so that true durations and latencies may have been longer than those reported.

The mortality experience was compared with Lombardy regional general population rates. The mortality for various cancers was: stomach $(\mathrm{O} / \mathrm{E}$ $=5 / 4 \cdot 1)$, leukaemia $(\mathrm{O} / \mathrm{E}=2 / 1 \cdot 0)$, and lymphosarcoma-reticulosarcoma $(\mathrm{O} / \mathrm{E}=4 / 0 \cdot 6, \mathrm{p}<0.05)$. When these diseases were examined for duration of exposure and for latency, there were no suggestions of an increase with longer duration or longer latency. In particular, the leukaemias both occurred among workers with < five years of exposure and within five years of first exposure. An examination of the subgroup licensed only for EtO handling showed a significant excess of haematopoietic cancers $(\mathrm{O} / \mathrm{E}=5 / 0 \cdot 7)$.

\section{Critique}

This study had a high mortality follow up rate $(>99 \%)$, but the average follow up time was short. There were no estimates of individual exposure levels. The estimated duration of exposure was inaccurate as well: workers received licences for five year periods, but their actual duration of exposure was unknown; also, some workers may have used EtO before being licensed.

Many of these workers apparently had exposures to other toxic chemicals (see table 3 ). The fact that workers were licensed to handle specific toxic gases meant there was some potential to try to isolate particular chemicals that might relate to a given cancer excess, but most such analyses were uninformative. ${ }^{18}$ However, they also reported the mortality experience of the subcohort who were licenced to handle only EtO.

The relatively small cohort size and short follow up time meant that the numbers of specific types of cancer were small. All 18 SMRs for the various specific types of cancer were $>1$; this is not very plausible and raises a question about the correctness of the calculations or the population rates. No information was given on brain cancer, although it 
can be deduced from their mortality tabulation that none occurred.

\section{Study methods}

To provide an overall quantitative summary of the results of these studies for the primary disease endpoints of interest we tabulated all the data and performed a summary meta-analysis of the Standardised Mortality (or Incidence) Ratios (SMRs). Several decisions were made regarding the inclusion or exclusion of specific studies in the meta-analyses. A reported but unpublished update by B Divine of the Morgan et $a l^{11}$ study was included with permission from the author. Workers in the Thiess $e t \mathrm{al}^{9}$ study who had been exposed to EtO for at least a year were also included in the subsequent study by Kiesselbach et al ${ }^{10}$ so if tabulations were available from both studies, only the Kiesselbach et al results were used, to avoid double counting. The Teta et al ${ }^{13}$ study represented a 10year update on most of the exposed workers in the Greenberg et $a l^{12}$ study, so only the results of Teta et al results were used (including some additional detailed unpublished tabulations provided by $\mathbf{M ~ J}$ Teta, 1992). Likewise, the study by Wong and Trent ${ }^{16}$ updated the results by Steenland et al ${ }^{14}$ for an additional year, so the overall results of Wong and Trent ${ }^{16}$ were used instead of the Steenland results. However, since Wong and Trent ${ }^{16}$ examined only duration and time of employment, rather than duration and time of exposure, the results of Steenland $e t a l^{14}$ were used for the temporal tabulations. In the tables for various causes of death, the reports included in the meta-analysis are indicated, together with the results of the metaanalysis.

No attempt was made to weight the studies according to quality because there is no objective way to do so. A number of different criteria for study quality could be applied, but it is unclear how one would weight the various criteria. It was considered that a subjective weighting scale would not be scientifically defensible.

Some cancer endpoints that appear to be of interest (for example, brain cancer) were reported on in only a fraction of the studies. It is often the case that authors of occupational studies report mainly on the principal disease endpoints (in this case, leukaemia) or ones that show positive results. This produces a bias in the literature because the "chance" positive results are more likely to get reported than chance null results. This potential for bias can sometimes be an important consideration in evaluating the summary results for a disease endpoint. When a particular cancer type was not reported, we have attempted to minimise this bias by determining, whenever possible, if no cancers of a given type had occurred. If so, approximate expected values were derived by indirect means.

Cancer incidence data have been used when available, but most EtO studies had only mortality data. The tables indicate where incidence data are being used. Incidence data and mortality data have been used interchangeably in the analyses. An underlying assumption in using mortality and incidence data together in a relative risk model is that the proportion of cases of a disease who die from it is the same for "spontaneous" cases and for cases caused by the exposure in question. For the diseases and exposure being considered, we are not aware that this assumption is materially violated.

A statistical concern in meta-analysis is how to deal with heterogeneity among estimates of risk. When the various studies being considered have very similar (homogeneous) findings, it is generally acceptable to combine them to derive overall estimates of risk. However, when the results are disparate (different studies have very different estimates of risk), it is less clear as to how to proceed. The first step is to determine whether there is statistical evidence of heterogeneity of risk. ${ }^{29}$ Since tests for heterogeneity generally have limited statistical power, a negative result should be treated with some caution. In order to increase the statistical power, we regarded a test as showing heterogeneity if the $\mathrm{p}$ value was $\leqslant 15 \%$.

When significant heterogeneity is found in as meta-analysis, several possible approaches have been suggested. The approach of ignoring the heterogeneity and calculating the overall SMR and its confidence interval in the same way as when the data are homogeneous has commonly been used, but its inadequacy has increasingly been recognised. ${ }^{30}{ }^{31}$ It can produce an overall estimate of risk with a narrow confidence interval that implies more precision in the risk estimate than the data warrant. A second approach is to calculate an estimate of the average risk and its variance which reflects both the "within study" variances and the "between study" heterogeneity among the estimates, ${ }^{30}$ which will create a wider, more realistic confidence interval. We used a simple variant of this approach, suggested by Armitage, ${ }^{32}$ which inflates the variance of the estimator by a factor derived from the heterogeneity test (a description is given in the Appendix). The present paper uses the first approach and, when there is evidence for heterogeneity, the second approach as well.

A second statistical concern pertains to the relative weighting of studies. One method to combine SMRs is by dividing the sum of the observed values across studies by the sum of the expected values across studies-that is, $\mathrm{SMR}_{\text {overall }}=(\Sigma \mathrm{O}) /(\Sigma \mathrm{E}) .{ }^{29}$ This ratio is then tested for significance and a confidence interval is estimated as if it were derived 
from a single study. This estimator has the implicit property that the study weights are proportional to the expected numbers of disease cases, which is intuitively sensible, and it can include even studies with no observed cases, unlike an alternative method. ${ }^{33}$

In the detailed tables, estimates of the Standardised Mortality (or Incidence) Ratios (SMRs) and the $95 \%$ confidence intervals $(95 \%$ CIs) are given for each study and for the combination of studies. The $95 \%$ CIs were calculated by the exact mid-P method based on the Poisson distribution. ${ }^{34}$ When there were over 100 observed cases an approximate method, attributed to Byar, ${ }^{29}$ was used. The outcome of the $\chi^{2}$ test for heterogeneity of the SMRs in individual studies is given. If there is statistical evidence of heterogeneity (using $\mathrm{p} \leqslant 0.15$ as the criterion), an estimate is given of the summary confidence interval adjusted for heterogeneity (see Appendix), and studies making the main contribution to the heterogeneity are mentioned.

Important clues in judging the causality of an association between an environmental exposure and a disease come from examining the doseresponse gradient and the temporality of the association. To evaluate the dose-response gradient, we examined the associations by duration of exposure and by intensity or frequency of exposure. (Tabulations were seldom available by cumulative exposure or by duration and intensity jointly.) To evaluate the temporality of associations, tabulations of risk by latency (attained years since first exposure) are shown.

To summarise the trends by exposure intensity or tumour latency, we performed a crude metaanalysis by summing each category across studies and testing for a trend in the summed results. This summation represents an aggregation of the results for the lowest, medium, and highest ranked groups. This procedure should be viewed as semi-quantitative at best and as only a rough overview, since the respective categories in various studies may represent quantitatively different exposure levels and the pooled results could therefore potentially be confounded. ${ }^{35}$ As an approximate guide, we tested for trends in the SMR exposure tabulations, ${ }^{29}$ with scores of 1,2 , and 3 assigned to the successive levels.

For duration of exposure, the studies presented from two to four subgroups with cut off points at varying durations. Fortunately, all the studies had a cut off point at 10 years, except for one study with an eight year cut off point. We therefore collapsed the data to $<10 v 10+$ years (or < eight $v$ eight + ) for analysis, except for leukaemia where the finer gradations are presented. An exact method was used to compare the SMRs of the two duration groups. ${ }^{29}$

Table 4 Leukaemia among exposed workers: ratios of observed to expected leukaemias and 95\% CIs, by individual study and overall meta-analysis

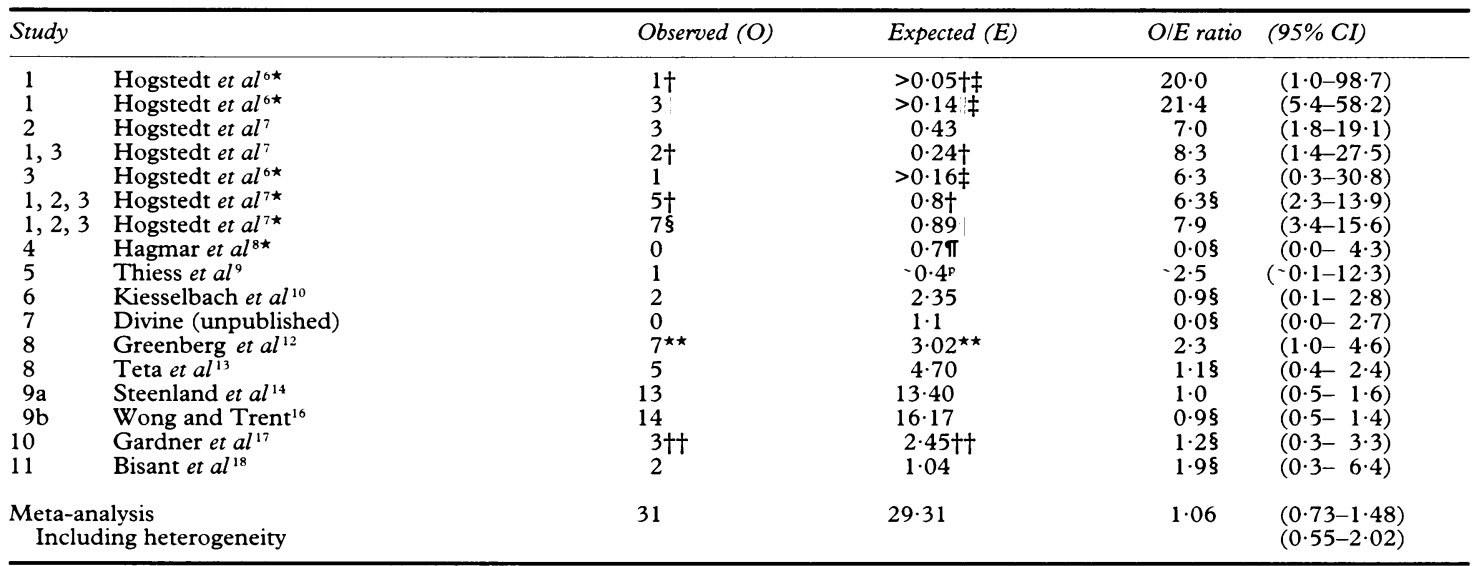

^Indicates a tally of incident cases; otherwise only mortality was assessed.

tExcludes two observed and 0.09 expected leukaemias prior to 1979 , which constituted the initial "case cluster".

$\ddagger$ In the latest update no more leukaemia cases had occurred, but updated expected values were not presented so this expected value is an underestimate.

$\S$ These studies were included in the meta-analysis.

Includes the initial "case cluster". The previous line in the table shows these data with the cluster excluded.

TExpected value also includes polycythemia vera and myelofibrosis, but this makes little difference. Among males these diseases together are only $2-6 \%$ as common as leukaemia according to German cancer registries. ${ }^{45}$

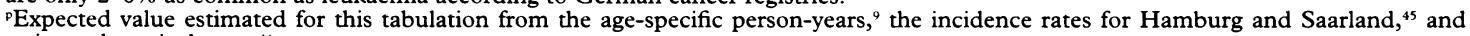
estimated survival rates. ${ }^{40}$

$\star \star$ Would be four observed and 2.6 expected if the leukaemias among workers in an ethylene chlorohydrin production department who had little EtO exposure were excluded.

$\dagger+$ Includes unpublished update of mortality. 


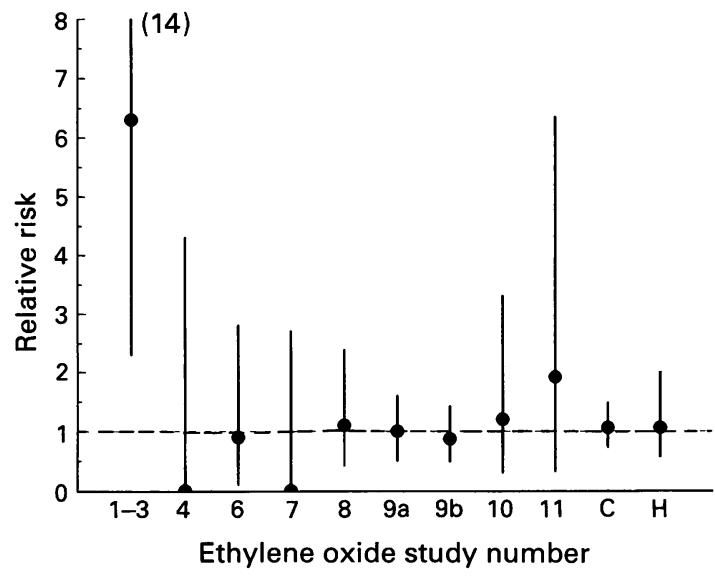

Figure 1 Leukaemia: SMRs and 95\% confidence intervals among EtO exposed workers, for individual studies and the combined studies.

\section{Results and discussion}

LEUKAEMIA

Table 4 and Figure 1 summarise the overall findings for leukaemia, based on 31 cases. An exceptionally high relative risk was seen in the initial report in 1979 by Hogstedt et $a l^{4}$ (study 1) of leukaemia among EtO exposed steriliser workers at a plant in Sweden, which was essentially a study based on a case cluster. To counter the "case cluster" interpretation Hogstedt et al have pointed out that "the hypothesis of a mutagenic and carcinogenic effect from ethylene oxide had been postulated" 7 some years before; nevertheless, the study was performed because of a report of the cluster to government authorities. ${ }^{4}$ Other studies by Hogstedt et al also showed an increased risk of leukaemia among EtO exposed workers. ${ }^{5}{ }^{6}$ However, a number of other investigators have reported studies of EtO exposed workers, some with much larger studies and with EtO exposure levels in the same range as the Hogstedt et al plants, and these reports have been essentially negative.

Excluding the initial case cluster report, the summary SMR (i.e., ratio of observed/expected cases) from the meta-analysis is 1.06 with a $95 \%$ $\mathrm{CI}$ of 0.73 to 1.48 . If the original case cluster were included, the SMR would be $1 \cdot 12$, which again is not a significant increase $(95 \%$ CI $0 \cdot 79-1 \cdot 56)$

A formal statistical test for heterogeneity of the leukaemia SMRs was highly significant $\left(\chi^{2}=23 \cdot 8\right.$, $7 \mathrm{df}, \mathrm{p}=0.001$ ). It was exclusively because of the findings in the studies of Hogstedt et al that the $\chi^{2}$ test rejected homogeneity of relative risks. Without these, the remaining studies were quite homogeneous (SMR $=0.91$; heterogeneity test, $p=0.78$ ), and the remaining relative risks and their confidence intervals overlap (fig 1). For the SMR of $\varnothing \vec{\varnothing}$ 1.06 based on all studies, the estimated $95 \% \mathrm{CI}$ taking into account the heterogeneity among studies was $0 \cdot 55-2 \cdot 02$.

One possible reason that most of the studies of

Table 5 Risk of leukaemia by intensity or frequency of exposure

\begin{tabular}{|c|c|c|c|c|}
\hline \multirow[b]{2}{*}{ Study } & & \multicolumn{3}{|c|}{ Intensity or frequency of exposure } \\
\hline & & Low SMR (O/E) & Intermediate $S M R(O / E)$ & High SMR $(O / E)$ \\
\hline 2 & Hogstedt $e t \mathrm{al}^{7}$ & $\begin{array}{l}\text { Unexposed } \\
0(0 / 0 \cdot 1)\end{array}$ & $\begin{array}{l}\text { Repairmen } \\
5 \cdot 0(1 / 0 \cdot 2)\end{array}$ & $\begin{array}{l}\text { Operators } \\
10.0(2 / 0 \cdot 2)\end{array}$ \\
\hline 4 & Hagman et al ${ }^{8}$ & $\begin{array}{l}<1 p p m-y r^{*} \\
1 \cdot 3(2 / 1 \cdot 52)\end{array}$ & $\begin{array}{l}1+p p m-y r^{*} \\
0(0 / 0 \cdot 2)\end{array}$ & \\
\hline 7 & Divine (unpublished) $\uparrow$ & & $\begin{array}{l}Q C \\
\text { laboratory or maintenance } \\
0(0 / \sim 0.81)\end{array}$ & $\begin{array}{l}\text { Operator } \\
0(0 / \sim 0 \cdot 61)\end{array}$ \\
\hline 8 & Teta et al ${ }^{13}$ & $\begin{array}{l}\text { Low } \ddagger \\
1 \cdot 8(3 / 1 \cdot 70)\end{array}$ & $\begin{array}{l}\text { Intermediate } \\
1 \cdot 1(1 / 0 \cdot 94)\end{array}$ & $\begin{array}{l}\text { High } \ddagger \\
0 \cdot 9(1 / 1 \cdot 12)\end{array}$ \\
\hline $9 a$ & Steenland et al ${ }^{14}$ & $\begin{array}{l}\text { Warehouse } \\
1.5(2 / 1.34)\end{array}$ & $\begin{array}{l}\text { Steriliser } \\
\text { area or } \\
\text { maintenance } \$ \\
1 \cdot 2(4 / 3 \cdot 43)\end{array}$ & $\begin{array}{l}\text { Steriliser or } \\
\text { production } \\
\text { operator } \\
1 \cdot 1(11 / 11 \cdot 56)\end{array}$ \\
\hline 10 & Gardner et al ${ }^{17}$ & $\begin{array}{l}\text { Unknown } \\
0(0 / 0.51)\end{array}$ & $\begin{array}{l}\text { Possible } \\
0(0 / 0.35)\end{array}$ & $\begin{array}{l}\text { Definite } \\
2 \cdot 4(3 / 1 \cdot 23)\end{array}$ \\
\hline Com & bined & $\begin{array}{l}\text { Low } \| \\
1 \cdot 5(7 / 4 \cdot 66)\end{array}$ & $\begin{array}{l}\text { Intermediate } \\
1.0(6 / 5.93)\end{array}$ & $\begin{array}{l}\text { High } \\
1 \cdot 2(17 / 14 \cdot 72)\end{array}$ \\
\hline
\end{tabular}

^Cumulative exposure (duration $x$ intensity).

†Expected values estimated by assuming that leukaemia constitutes $37 \%$ of total haematopoietic cancer mortality (based on US male rates, ages $\left.20-74^{46}\right)$. Note that these worker categories are not mutually exclusive; some workers are in multiple categories.

$\neq$ Those assigned for $\geqslant$ two years to a high (/intermediate/low) department.

§Those who worked intermittently in the steriliser area.

|Excludes the "unknown" category in the study of Gardner $e t$ al ${ }^{17}$. 
Table 6 Risk of leukaemia by duration of exposure

\begin{tabular}{|c|c|c|c|c|}
\hline \multirow[b]{2}{*}{ Study } & & \multicolumn{3}{|c|}{ Duration of exposure $(y)$} \\
\hline & & \multirow{2}{*}{$\begin{array}{l}S M R(O / E) \\
1-4 y \\
0(0 / 0 \cdot 06)\end{array}$} & \multirow{2}{*}{$\begin{array}{l}S M R(O / E) \\
5-9 y \\
25(1 / 0.04)\end{array}$} & \multirow{2}{*}{$\begin{array}{l}S M R(O / E) \\
10+y \\
12 \cdot 5(1 / 0 \cdot 08)\end{array}$} \\
\hline 2 & Hogstedt et al ${ }^{6}$ & & & \\
\hline $1,2,3$ & Hogstedt et $a l^{7 \star}$ & & $\begin{array}{l}1-9 y \\
6 \cdot 7(2 / 0 \cdot 3)\end{array}$ & $\begin{array}{l}10+y \\
13.6(3 / 0 \cdot 22)\end{array}$ \\
\hline 5 & Thiess $e t a l^{9}$ & $\begin{array}{l}0.5-9 y \\
20(1 / 0.05)\end{array}$ & $\begin{array}{l}10-19 y \\
0(0 / 0 \cdot 045)\end{array}$ & $\begin{array}{l}20+y \\
0(0 / 0 \cdot 053)\end{array}$ \\
\hline 7 & Divine (unpublished) $\uparrow$ & $\begin{array}{l}<10 y \\
0(0 / \sim 0 \cdot 18)\end{array}$ & $\begin{array}{l}10-19 y \\
0(0 / \sim 0.30)\end{array}$ & $\begin{array}{l}20+y \\
0(0 / \sim 0.63)\end{array}$ \\
\hline 8 & Teta et al ${ }^{13}$ & $\begin{array}{l}<10 y \\
0.6(2 / 3.58)\end{array}$ & $\begin{array}{l}10-19 y \\
2 \cdot 7(2 / 0 \cdot 73)\end{array}$ & $\begin{array}{l}20+y \\
2 \cdot 6(1 / 0 \cdot 39)\end{array}$ \\
\hline $9 a$ & Steenland $e t a^{14}$ & $\begin{array}{l}<1 y \\
1.0(3 / 3.06)\end{array}$ & $\begin{array}{l}1-7 y \\
0.9(5 / 5.75)\end{array}$ & $\begin{array}{l}8+y \\
1 \cdot 1(5 / 4 \cdot 59)\end{array}$ \\
\hline 10 & Gardner et al ${ }^{17}$ & $\begin{array}{l}0-4 y \\
2.2(1 / 0.45)\end{array}$ & $\begin{array}{l}5-9 y \\
5 \cdot 0(1 / 0 \cdot 20)\end{array}$ & $\begin{array}{l}10+y \\
5 \cdot 3(1 / 0 \cdot 19)\end{array}$ \\
\hline 11 & Bisanti et al ${ }^{18}$ & $\begin{array}{l}0-4 y \\
8 \cdot 2(2 / 0.24)\end{array}$ & $\begin{array}{l}5-9 y \\
0(0 / \sim 0.49) \ddagger\end{array}$ & $\begin{array}{l}10+y \\
0(0 / \sim 0.30) \ddagger\end{array}$ \\
\hline \multicolumn{2}{|c|}{ Combined } & $\begin{array}{l}\text { Brief } \\
1 \cdot 2(9 / 7 \cdot 62)\end{array}$ & $\begin{array}{l}\text { Intermediate } \\
1.4(11 / 7 \cdot 86)\end{array}$ & $\begin{array}{l}\text { Long } \\
1 \cdot 7(11 / 6 \cdot 45)\end{array}$ \\
\hline
\end{tabular}

*Includes the two leukaemias from the initial "case cluster" report" because information was not available to permit excluding them, but excludes the leukaemia data reported in the preceding line of the table.

†Expected values estimated by assuming that leukaemia constituted $37 \%$ of total haematopoietic cancer mortality (based on U.S. male rates, ages $\left.20-74^{46}\right)$. The expected values for $10-19$ and $20+$ years further assume that the expected leukaemias are proportional to the total expected cancers for these two categories.

$\ddagger$ Expected value estimated by assuming that the expected leukaemias for $\geqslant 5 \mathrm{y}$ duration were distributed in proportion to the expected values for all haematopoietic cancers.

leukaemia were negative is that including many workers with relative low or brief exposures in the results may have "diluted" any positive effects among the more highly exposed when the overall study results were examined. ${ }^{3637}$ To try to obviate this potential problem, the leukaemia results were examined, where possible, by intensity or duration of exposure. Tabulations of leukaemia risk by frequency or intensity of exposure are shown in table 5. When the SMRs were examined, there were suggestions of positive trends by frequency and intensity of exposure in the studies by Hogstedt et al and Gardner et $a l,{ }^{17}$ based on six leukaemias collectively, while the trend is in the opposite direction in the studies by Teta $e t$ al and Steenland et al, based on 22 leukaemias collectively. In short, there is no consistency in the trends by frequency and intensity of exposure, nor are any of the trends significant. The SMRs for all studies combined do not indicate a trend in leukaemia risk with respect to frequency and intensity of exposure (table 5).

Breakdowns of leukaemia risk by duration of exposure are shown in table 6 . The data reported by Teta $e t a l^{13}$ showed some suggestion of a trend but were not significant $(p=0 \cdot 11)$. Similarly, the trends in the studies by Hogstedt et al and Gardner et al ${ }^{17}$ were based on few cases and were nonsignificant. None of the other studies suggested an increasing gradient of risk by duration of exposure. An over-all test for trend by duration of exposure was null $(p=0.41)$ as was the duration data dichotomised at $<10 v \geqslant 10$ years (not shown) $(\mathrm{p}=$ $0 \cdot 59)$.

In a recent analysis of leukaemia $v$ cumulative EtO exposure in the largest EtO cohort studied, Stayner et $a l^{15}$ found only a weak association that was not statistically significant $(p=0 \cdot 15)$. This represents the best examination of exposureresponse available and suggests there is little association between EtO and leukaemia.

The histological types of the reported leukaemias in exposed workers included: acute myeloid leukaemia, eight; chronic myeloid, six; myeloid NOS (not otherwise specified), one; acute lymphatic, one; chronic lymphatic, four; lymphatic NOS, two; acute leukaemia NOS, four; other, unspecified, six. This tabulation suggests a preponderance of myeloid-type leukaemia among those with EtO exposure (15 myeloid $v$ seven lymphatic), whereas lymphatic and myeloid leukaemia occur with about equal frequency among adult males in the general population. ${ }^{38}$

The findings on leukaemia from the various studies were examined in more detail because of their fundamental importance. Table 2 brings together some of the description of the exposure and nature of the workplace for each study. In 
general the reported exposures to EtO show higher levels prior to 1960 , and especially back in the 1920 s to 1940s. The estimates of early exposure levels are based largely on judgement, however, since very few measurements were made prior to the mid-1970s. Hence, the early estimates may be rather inaccurate.

In viewing the results for leukaemia in table 4, the three studies by Hogstedt et al ${ }^{4-7}$ stand out because they are the only ones that are positive by conventional statistical criteria. The difference in relative risks between the studies of Hogstedt et $a^{67}$ and the others could possibly be due to the following italicised factors.

\section{Chance}

This seems to be an unlikely explanation in view of the consistency among the three Hogstedt et al studies.

\section{Selection bias or information bias}

Are the Hogstedt et al (and other) studies all appropriately designed and analysed so that they are unbiased? On this score, the initial report by Hogstedt et $a l^{4}$ should be discounted: it came about because of a report to government authorities of a cluster of cases at that plant. It is well known that initial cluster reports should not be included in determining causality or assessing the magnitude of risk. ${ }^{21} 22$ If one removes the initial case cluster (and the corresponding expected values) then only one subsequent leukaemia has occurred in Hogstedt's study no 1. A possible issue of selection bias in Hogstedt's study no 2 has also been raised by others. ${ }^{39}$ The study cohort consists of workers who participated in a screening study performed by Ehrenberg and coworkers in 1959-61, who were evidently only a fraction of the workers at the plant. ${ }^{7}$ Details about the methods of identification and follow up of the cohort are sparse, but from what is given there is no obvious mechanism by which it would produce qualitative bias. Since the screening and cohort definition were performed at the beginning of the period of observation, it should not result in bias in the study through selective attrition or other mechanisms. Nevertheless, the basis for selection of the workers for initial screening is unknown, and it is possible that self selection related to existing blood problems could have occurred. Applying the criteria of study quality mentioned to the remaining published studies, there were no obvious flaws in their designs. The analyses of the Hogstedt et al studies were of marginal adequacy - the expected values indicated in various reports do not always agree, and the final report indicated no new leukaemias but failed to report the updated expected values.
High level of EtO exposure in the studies of Hogstedt et al

Are the Hogstedt studies positive because their exposure levels were higher than those of the other studies? The first two studies ${ }^{4-7}$ reported exposure levels that were rather high, especially in earlier times; estimated mean exposures were more than $10 \mathrm{ppm}$ and up to $50 \mathrm{ppm}$. However, these exposure levels were similar to ones reported by Greenberg $e t a l^{12}$ and Teta $e t a l^{13}$ who did not find an excess of leukaemia in their cohort (once a subgroup was removed who had relatively little EtO exposure but substantial exposure to chemicals involved in the production of ethylene chlorohydrin). That the Greenberg et $a l^{12}$ and Teta $e a{ }^{13}$ cohort had high levels of exposure in the early decades is attested to by early measurements the company had made ${ }^{26}$ and by the fact that the plant medical department records showed numerous worker visits for acute EtO-exposure symptoms. ${ }^{12}$ Hagmar $e t \mathrm{al}^{8}$ and Thiess $e t \mathrm{al}^{9}$ also reported exposure levels among some workers that appear to be comparable to the EtO levels estimated by Hogstedt et al. Their results were also negative, but the short period of follow up and the modest number of workers with these high exposure levels lessen the meaningfulness of their negative find- 8 ings. All in all, there does not seem to be persuasive evidence that the positive results in the Hogstedt studies are attributable to the EtO-exposure levels being higher than in other studies.

Confounding exposures to other carcinogenic workplace exposures

The findings on leukaemia were examined in relation to the nature of the workforce and type of exposure for the various studies. There have been four studies of sterilisation workers (Hogstedt no 1, Hagmar et al, ${ }^{8}$ Steenland et al ${ }^{14}$ and Wong and Trent, ${ }^{16}$ and the hospital workers in the cohort of Gardner et $a{ }^{17}$ ). After excluding the initial leukaemia cluster in the original Hogstedt et al study ${ }^{4}$ as in the earlier overall meta-analysis (table 4), $\mathrm{O} / \mathrm{E}=15 / \sim 17 \cdot 89=0.84(95 \%$ CI $0 \cdot 49-1 \cdot 35)$ for the combined EtO steriliser studies. Even with the original leukaemia cluster included, the $\mathrm{O} / \mathrm{E}$ ratio was only $17 / \sim 17.98=0.95(p=0.84,95 \% \mathrm{CI}$ $0 \cdot 57-1 \cdot 48)$. Among workers involved in the production of EtO and its use in manufacture (Hogstedt study no 2, Hogstedt study no 3, Kiesselbach et al, Divine, Teta et al, Gardner et al production workers), the observed/expected ratio is $14 / \sim 10 \cdot 25=1.37(95 \%$ CI $0 \cdot 78-2 \cdot 24)$. While this is not statistically significant $(p=0.25)$, the increased risk is nevertheless somewhat suggestive.

To take a closer look at this result, we examined whether the risks were comparable in plants that had used the chlorohydrin process $v$ the direct 
oxidation process for production of EtO. The Hogstedt study no 2 plant used only the chlorohydrin process and had $\mathrm{O} / \mathrm{E}=4 / 0 \cdot 52=7 \cdot 7$, while Divine reported on those who had had exposure during the time the chlorohydrin process was used: $\mathrm{O} / \mathrm{E}=0 / 0 \cdot 9$. The Hogstedt study no 3 plant used only the direct oxidation process and Divine reported on workers exposed only from the direct oxidation process, with a combined $\mathrm{O} / \mathrm{E}=2 / 0 \cdot 24=$ $8 \cdot 3$. Unfortunately, most plants had used both processes, and the studies did not provide separate tabulations for workers who were exposed to just one of the processes; these included the plants studied by Thiess $e t$ al, Kiesselbach $e t$ al, Teta et al and Gardner et al which had a combined $\mathrm{O} / \mathrm{E}=$ $10 / 9.48=1.05$. In summary, there is inadequate evidence to say that an elevated risk is derived from EtO production by the chlorohydrin process but not by the direct oxidation process, or vice versa.

It is notable, however, that the subgroup in the study by Greenberg et al who worked in a department that produced ethylene chlorohydrin (but had little EtO exposure) had an excess of leukaemia, and that the Hogstedt study no 2 which had the largest leukaemia excess, also produced ethylene chlorohydrin in the same department where EtO was produced. It is plausible that some chemical involved in ethylene chlorohydrin production may be leukaemogenic. In fact, the production involved ethylene dichloride, a suspected animal carcinogen, with air concentrations of about $100 \mathrm{mg} / \mathrm{m}^{3}$ in the Hogstedt study no 2 plant, and bis-(2-chloroethyl) ether (air concentration of about $0.05 \mathrm{mg} / \mathrm{m}^{3}$ ) for which there is limited evidence of animal carcino- genicity. It should also be mentioned that the Hogstedt study no 2 plant produced several chlorinated organic products (chloroform, chlorinated acetals, chloral and DDT), which appear to be unique to this EtO study, and which would have involved a variety of chemicals in their production. Hence, confounding exposure to other workplace chemicals is a distinct possibility to explain Hogstedt's elevated rates in the production facility. Or, alternatively, there may be some joint (synergistic) effect of EtO plus some other chemical.

It has sometimes been hypothesised that intermittent, peak exposures may confer more risk than the same total amount of exposure delivered at a reasonably constant, lower rate. If this were true, one might expect to see more risk among sterilant workers than production workers, since sterilant workers historically had a pattern of high exposures when the autoclaves were opened and low otherwise. The lack of an excess among steriliser workers is not supportive of this hypothesis.

Several studies that provided information on leukaemia latency (i.e., time between first EtO exposure and leukaemia diagnosis/death) were suggestive of an increase in leukaemia risk over time (table 7), especially the studies by Steenland $e t$ $a l^{14}(\mathrm{p}=0.06)$ and Gardner et al ${ }^{17}(\mathrm{p}=0.07)$, but the studies by Teta $e t a l^{13}$ and Bisanti et al ${ }^{18}$ were in the negative direction. For the combined studies there was a suggestion that risk increases with time (trend test, $\mathrm{p}=0.07$ ). In addition, the combined SMR for the 20 + year latency category was significantly elevated $(p=0.02)$. There are several possible explanations of these findings. Firstly, it may

Table 7 Risk of leukaemia by latency (interval since first exposure to EtO)

\begin{tabular}{|c|c|c|c|c|}
\hline \multirow[b]{2}{*}{ Study } & & \multicolumn{3}{|l|}{ Latency $(y)$} \\
\hline & & $S M R(O / E)$ & $S M R(O / E)$ & $S M R(O / E)$ \\
\hline 2 & Hogstedt $e t a l^{5}$ & \multirow{6}{*}{$\begin{array}{l}<10 y \\
0(0 / \sim 0 \cdot 08) \ddagger \\
0-9 y \\
2 \cdot 7(2 / 0 \cdot 74) \\
<10 y \\
0 \cdot 4(2 / 5 \cdot 00) \\
<10 y \\
0(0 / 0 \cdot 23) \\
<10 y \\
4 \cdot 3(2 / 0.47)\end{array}$} & \multirow{6}{*}{$\begin{array}{l}10-19+{ }^{*} y \\
7 \cdot 7(1 / 0 \cdot 13) \\
10+y \\
6 \cdot 7(1 / 0 \cdot 15) \\
10-19 y \\
0(0 / 1 \cdot 16) \\
10-20 y \\
0 \cdot 9(5 / 5 \cdot 61) \\
10-19 y \\
0(0 / 0 \cdot 27) \\
10-19 y \\
0(0 / \sim 0 \cdot 35) \S\end{array}$} & \multirow[t]{2}{*}{$\begin{array}{l}20+y \dagger \\
14 \cdot 3(2 / 0 \cdot 14)\end{array}$} \\
\hline 5 & Thiess et al ${ }^{9}$ & & & \\
\hline 8 & Teta et al ${ }^{13}$ & & & $\begin{array}{l}20+y \\
1 \cdot 1(3 / 2 \cdot 82)\end{array}$ \\
\hline $9 a$ & Steenland et al ${ }^{14}$ & & & $\begin{array}{l}>20 y \\
1.8(5 / 2 \cdot 79)\end{array}$ \\
\hline 10 & Gardner et al ${ }^{17}$ & & & $\begin{array}{l}20+y \\
8.6(3 / 0.35)\end{array}$ \\
\hline 11 & Bisanti et al ${ }^{18}$ & & & $\begin{array}{l}20+y \\
0(0 /-0 \cdot 22) \S\end{array}$ \\
\hline \multicolumn{2}{|c|}{ Combined } & $\begin{array}{l}\text { Brief } \\
0.9(6 / 6.52)\end{array}$ & $\begin{array}{l}\text { Intermediate } \\
0.9(7 / 7.67)\end{array}$ & $\begin{array}{l}\text { Long } \\
2 \cdot 1(13 / 6 \cdot 32)\end{array}$ \\
\hline
\end{tabular}

*Includes the 10-19 year latency experience for all workers with $1+$ year of exposure plus the $20+$ year latency experience for workers with 1-9 years of exposure.

tIncludes only those with $10+$ years of exposure.

$\neq$ Expected value calculated by assuming that $20 \%$ of the expected haematopoietic cancers were leukaemic, based on the values for their $10+$ year latency group.

§Expected value estimated by assuming that the expected leukaemias for $\geqslant 10$ years latency were distributed in proportion to the expected values for all haematopoietic cancers.

$\|$ This SMR is significantly elevated $(p=0.02)$. Test for trend in SMR was borderline $(p=0.07)$. 
Table 8 Non-Hodgkin's lymphoma* mortality among exposed workers: ratios of observed to expected cancers by individual study and overall meta-analysis

\begin{tabular}{|c|c|c|c|c|}
\hline \multicolumn{2}{|l|}{ Study } & $\begin{array}{c}\text { Observed (O) } \\
1 \\
1 \\
1\end{array}$ & $\begin{array}{l}\text { Expected (E) } \\
\sim 0.76 \dagger \\
\sim 0.73 \\
\sim 0.60 \S\end{array}$ & $\begin{array}{l}\text { O/E ratio }(95 \% C I) \\
1 \cdot 3(0 \cdot 1-6 \cdot 5) \\
1 \cdot 4(0 \cdot 1-6 \cdot 8) \\
1.7(0 \cdot 1-8 \cdot 2)\end{array}$ \\
\hline $\begin{array}{l}1,2,3 \\
4 \\
5 \\
7 \\
8 \\
9 \mathrm{a} \\
9 \mathrm{~b} \\
10 \\
11\end{array}$ & $\begin{array}{l}\text { Hogstedt et al }{ }^{7} \\
\text { Hagmar } \text { et al }^{8} \\
\text { Thiess et al } \\
\text { Divine (unpublished data) } \\
\text { Teta et al }{ }^{13} \\
\text { Steenland et al }{ }^{14} \\
\text { Wong and Trent } \\
\text { Gardner et al }{ }^{17} \\
\text { Bisanti et al }{ }^{18}\end{array}$ & $\begin{array}{r}1 \\
1 \\
1 \\
0 \\
2 \\
16 \\
18 \\
4 \\
4\end{array}$ & $\begin{array}{l}\sim 0.76 \dagger \\
\sim 0 \cdot 73 \\
\sim 0.60 \S \\
\sim 1 \cdot 0 \| \\
\sim 4 \cdot 19 \\
12 \cdot 01 \\
12 \cdot 74 \\
1 \cdot 62 \\
\sim 1 \cdot 38^{\star \star}\end{array}$ & $\begin{array}{l}1.3(0 \cdot 1-6 \cdot 5) \\
1.4(0 \cdot 1-6 \cdot 8) \\
1 \cdot 7(0 \cdot 1-8 \cdot 2) \\
0 \cdot 0(0 \cdot 0-3 \cdot 0) \\
0.5(0 \cdot 1-1 \cdot 6) \\
1 \cdot 3(0 \cdot 8-2 \cdot 1) \\
1.4(0.9-2 \cdot 2) \\
2.5(0 \cdot 8-6 \cdot 0) \\
2.9(0.9-7 \cdot 0)\end{array}$ \\
\hline \multicolumn{2}{|c|}{ Meta-analysist† } & 31 & 22.93 & $1.35(0.93-1.90)$ \\
\hline
\end{tabular}

*Non-Hodgkin's lymphoma includes ICD9 codes 200 and 202.

†Expected value estimated by assuming that non-Hodgkin's lymphoma constitutes $39 \%$ of total haematopoietic cancer mortality (based on United States white male and female rates, ages 20-74, weighted according to the sex ratio in the study group ${ }^{46}$ ). The observed number excludes a case of Waldenstrom's macroglobulinemia reported by Hogstedt $e t$ al, which is not coded as a neoplasm in either ICD-8 or ICD-9.

¥Incidence of cancer is given. Expected value estimated by assuming that non-Hodgkin's lymphoma constitutes $56 \%$ of "lymphoma and myeloma" (ICD-7 codes 200-203) (based on Swedish male and female incidence rates weighted according to the sex ratio in the study group, ages $\left.20-74^{38}\right)$.

§The published expected value was based on only ICD-9 diagnostic code 200, rather than codes 200 and 202. From the Hamburg and Saarland, Germany Cancer Registries (males, ages 20-74) 38 we estimated that code 202 was $253 \%$ as frequent as code 200 and incremented their expected value by $253 \%$. Expected value estimated by assuming that non-Hodgkin's lymphoma constitutes $64 \%$ of nonleukaemic haematopoietic cancer mortality (based on United States white male rates, ages $20-74^{46}$ ).

|Estimated by subtracting Hodgkin's disease, leukaemia, and the estimated fraction attributable to multiple myeloma (based on United States white male mortality rates, ages $20-74^{46}$ ) from total lymphopoietic cancer.

ףEstimated by subtracting the estimated fraction ${ }^{46}$ attributable to multiple myeloma (ICD-9 203; (31\% based on United States white male mortality rates, ages 20-7446) from the combined ICD-9 codes 200, 202, and 203).

pIncludes their categories "lymphosarcoma-reticulosarcoma" and "non-Hodgkin's lymphoma."

$\star \star$ The published expected value was based on only ICD9 diagnostic code 200, rather than codes 200 and 202 . From the Lombardy, Italy Cancer Registry (males, ages 20-74) we estimated that code 202 was $136 \%$ as frequent as code 200 and incremented their expected value by $136 \%$.

t†All studies were included except the data of Steenland $e t$ al ${ }^{14}$ which are incorporated in the results of Wong and Trent. ${ }^{16}$

represent a chance finding, given the large number of statistical tests conducted. Secondly, this may be a real effect, that is, EtO has a leukaemogenic effect with a long induction latency period. This is consistent with the temporal relationship expected for cancers caused by tumour initiating agents. Thirdly, the effect may become evident in later years largely because of the additional exposure incurred over the course of time since first expo-

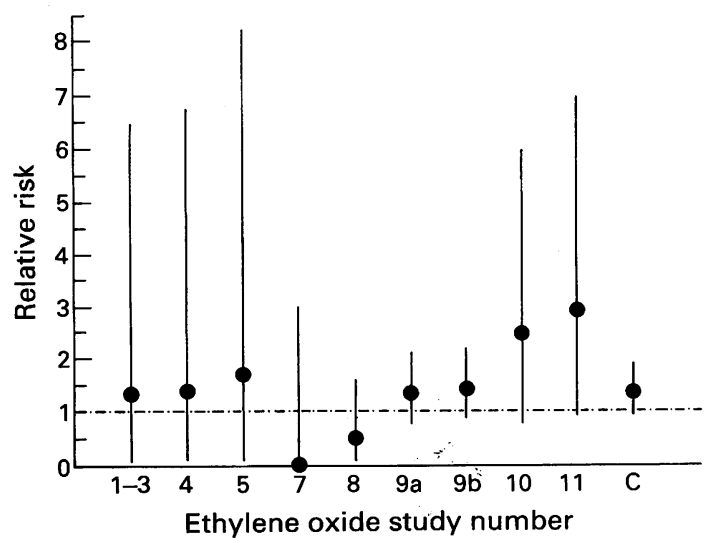

Figure 2 Non-Hodgkin's lymphoma: SMRs and 95\% confidence intervals among EtO exposed workers, for individual studies and the combined studies. sure. This, again, presupposes a genuine effect. This interpretation is made somewhat less likely by the fact that the trend by duration of exposure was marginal and there was no trend by intensity/frequency of exposure or by cumulative exposure.

In summary, the temporal data are consistent with a causal interpretation, but a clear gradient in risk by duration or intensity of exposure would be more convincing. Nevertheless, it will be important tofollow up these cohorts for longer periods of time in order to increase the precision of the risk estimates and further document whether there is an increase in leukaemia risk by amount of exposure and after a longer latency period.

\section{NON-HODGKIN'S LYMPHOMA}

When leukaemia risk is in question, it is also prudent to examine other haematopoietic malignancies, as the same pluripotent stem cells give rise to various types of lymphatic and haematopoietic cells. Firstly, the histological types of haematopoietic malignancy were examined to determine if there was any unusual pattern. The cases included seven Hodgkin's disease, 26 non-Hodgkin's lymphomas, four multiple myelomas, two polycythemia vera, and six with type not reported. The relative prevalence of these types suggests that the proportion of cases of non-Hodgkin's lymphomas is about what might be expected (about $65 \%$ ) in a 
Table 9 Morphology from non-Hodgkin's lymphoma by intensity or frequency of exposure

\begin{tabular}{|c|c|c|c|c|}
\hline \multirow{2}{*}{\multicolumn{2}{|c|}{ Study }} & \multicolumn{3}{|c|}{ Intensity or frequency of exposure } \\
\hline & & \multirow[t]{2}{*}{ Low SMR (O/E) } & \multirow{2}{*}{$\begin{array}{l}\text { Intermediate } S M R(O / E) \\
\text { Quality control } \\
\text { laboratory or maintenance } \\
0(0 / \sim 0.74)\end{array}$} & \multirow{2}{*}{$\begin{array}{l}\text { High SMR }(O / E) \\
\text { Operator } \\
0(0 / \sim 0 \cdot 57)\end{array}$} \\
\hline 7 & Divine (unpublished data) ${ }^{\star} \dagger$ & & & \\
\hline 8 & Teta et al ${ }^{13 \star} \ddagger$ & $\begin{array}{l}\text { Low } \\
0 \cdot 6(1 / \sim 1 \cdot 78)\end{array}$ & $\begin{array}{l}\text { Intermediate } \\
1 \cdot 1(1 / \sim 0.94)\end{array}$ & $\begin{array}{l}\text { High } \\
0(0 / \sim 1 \cdot 16)\end{array}$ \\
\hline & Steenland et al ${ }^{14}$ & $\begin{array}{l}\text { Warehouse } \\
0.5(1 / 2.03)\end{array}$ & $\begin{array}{l}\text { Steriliser } \\
\text { area or } \\
\text { maintenance } \\
1 \cdot 1(6 / 5 \cdot 41)\end{array}$ & $\begin{array}{l}\text { Steriliser or } \\
\text { production } \\
\text { operator } \\
1 \cdot 1(19 / 17 \cdot 75)\end{array}$ \\
\hline & ombined & $\begin{array}{l}\text { Low } \\
0 \cdot 5(2 / 3 \cdot 81)\end{array}$ & $\begin{array}{l}\text { Intermediate } \\
1.0(7 / 7 \cdot 09)\end{array}$ & $\begin{array}{l}\text { High } \\
1.0(19 / 19 \cdot 48)\end{array}$ \\
\hline
\end{tabular}

^Expected values estimated by assuming that leukaemia constitutes $39 \%$ of total haematopoietic cancer mortality (B Divine study) and that non-Hodgkin's lymphoma constitutes $68 \%$ of the ICD9 codes $200-203,208$ (B Divine and Teta et al $^{13}$ studies; based on United States white male rates, ages $20-74^{46}$ ).

†These three worker categories are not mutually exclusive; some workers are in multiple categories.

$¥$ Assigned for $\geqslant 2$ years to a high (/intermediate/low) department.

$\S$ Those who worked intermittently in the steriliser area.

Table 10 Cancer mortality by duration of exposure: non-Hodgkin's lymphoma, stomach cancer, brain and nervous system cancer, and pancreatic cancer

\begin{tabular}{|c|c|c|}
\hline \multirow[b]{2}{*}{ Study } & \multicolumn{2}{|l|}{ Duration of exposure } \\
\hline & $0-9$ y SMR (O/E) & $\geqslant 10$ y SMR $(O / E)$ \\
\hline $\begin{array}{ll}\text { Non-Hodgkin's lymphoma: } \\
\text { 1, 2, } 3 & \text { Hogstedt } e t \text { al } \\
7 \mathrm{~b} & \text { Divine (unpublished data)† } \\
8 & \text { Teta } \text { et al } l^{13 \dagger} \\
8 \mathrm{a} & \text { Steenland } e t \text { al }{ }^{14} \ddagger \\
\text { 9a } & \text { Bisanti } \text { et } a l^{18 \S} \\
11 & \\
\text { Combined }\end{array}$ & $\begin{array}{ll}2 \cdot 6 & (1 / \sim 0 \cdot 39) \\
0 & (0 / \sim 0 \cdot 13) \\
0 \cdot 3 & (1 / \sim 3 \cdot 10) \\
1 \cdot 2 & (9 / \sim 7 \cdot 54) \\
4 \cdot 3 & (4 / \sim 0.93) \\
1 \cdot 2 & (15 / 12 \cdot 09)\end{array}$ & $\begin{array}{ll}0 & (0 / \sim 0 \cdot 41) \\
0 & (0 / \sim 0 \cdot 88) \\
1 \cdot 0 & (1 / \sim 1 \cdot 03) \\
1 \cdot 6 & (7 / 4 \cdot 47) \\
0 & (0 / \sim 0 \cdot 46) \\
1 \cdot 1 & (8 / 7 \cdot 25)\end{array}$ \\
\hline 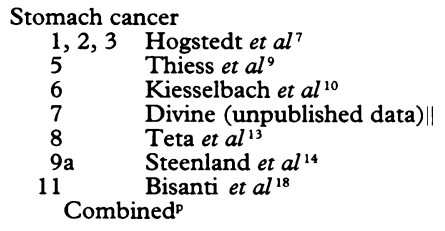 & $\begin{array}{ll}4 \cdot 8 & (4 / 0 \cdot 83) \\
4 \cdot 8 & (3 / 0 \cdot 62) \\
1 \cdot 7 & (5 / 3 \cdot 02) \\
0 & (0 / / 0 \cdot 09) \\
1 \cdot 6 & (6 / 3 \cdot 69) \\
1 \cdot 0 & (7 / 7 \cdot 06) \pi \\
1 \cdot 2 & (3 / 2 \cdot 41) \\
1 \cdot 5 & (25 / 17 \cdot 10)\end{array}$ & $\begin{array}{ll}5 \cdot 8 & (6 / 1 \cdot 04) \\
0 \cdot 8 & (1 / 1 \cdot 30) \\
1 \cdot 3 & (9 / 7 \cdot 13) \\
0 & (0 / \sim 0 \cdot 83) \\
1 \cdot 5 & (2 / 1 \cdot 31) \\
0 \cdot 8 & (4 / 4 \cdot 89) \\
1 \cdot 2 & (2 / 1 \cdot 65) \\
1 \cdot 4 & (23 / 16 \cdot 85)\end{array}$ \\
\hline 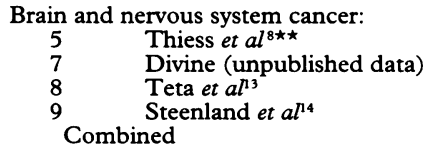 & $\begin{array}{ll}0 & (0 / 0 \cdot 04) \\
0 & (0 / 0 \cdot 17) \\
1 \cdot 6 & (5 / 3.06) \\
0.4 & (3 / 7 \cdot 28) \dagger \dagger \\
0.8 & (8 / 10 \cdot 55)\end{array}$ & $\begin{aligned} 25.0 & (1 / 0.04) \\
3.3 & (3 / 0.91) \\
1.1 & (1 / 0.94) \\
0.8 & (3 / 3.95) \\
1.4 & (8 / 5.84)\end{aligned}$ \\
\hline $\begin{array}{cc}\text { Pancreatic cancer: } \\
7 & \text { Divine (unpublished data) } \\
8 & \text { Teta } \text { et al } \text { l }^{13} \\
9 \mathrm{a} & \text { Steenland } \text { et al }{ }^{14} \\
11 & \text { Bisanti } \text { et } \text { al }^{18} \\
11 & \text { Combined }\end{array}$ & $\begin{array}{lc}0 & (0 / 0 \cdot 13) \\
0 \cdot 6 \quad(3 / 4 \cdot 87) \\
1 \cdot 2 & (12 / 9 \cdot 68) \\
0 \quad(0 / 0 \cdot 70) \\
1 \cdot 0 & (15 / 15 \cdot 38)\end{array}$ & $\begin{array}{ll}2 \cdot 2 & (3 / 1 \cdot 36) \\
0 \cdot 6 & (1 / 1 \cdot 71) \\
0 \cdot 6 & (4 / 7 \cdot 27) \\
6 \cdot 3 & (3 / 0 \cdot 48) \\
1 \cdot 0 & (11 / 10 \cdot 82)\end{array}$ \\
\hline
\end{tabular}

`Expected values estimated by assuming that non-Hodgkin's lymphoma constituted $64 \%$ of non-leukaemic haematopoietic cancers, based on U.S. male and female white mortality rates weighted by the sex ratio in the study group, ages $20-74 .{ }^{46}$

†Expected values estimated by assuming that non-Hodgkin's lymphoma constitutes $69 \%$ of the ICD9 codes $200,202,203,208$ (based on U.S. white male mortality rates, ages $20-74^{46}$ ).

‡Breakdown represents $1-7 v \geqslant 8+$ years.

$\oint$ Bisanti provided an expected value based on only ICD9 diagnostic code 200, rather than codes 200 and 202. From the Lombardy, Italy Cancer Registry ${ }^{38}$ (males, ages 20-74) we estimated that code 202 was $136 \%$ as frequent as code 200 and incremented their expected value by $136 \%$.

|Expected values estimated by assuming that stomach cancer constitutes $12.8 \%$ of total digestive cancer mortality (based on U.S. white male rates, ages $20-74^{46}$ ).

TThe expected value for one subgroup was estimated by assuming proportionality between stomach cancer and total-cancer expected values for the subgroup as compared with the other groups.

${ }^{\mathrm{P} C o m b i n e d ~ t a b u l a t i o n ~ e x c l u d e s ~ t h e ~ s t u d y ~ b y ~ T h i e s s ~ b e c a u s e ~ i t ~ i s ~ r e d u n d a n t ~ w i t h ~ t h e ~ K i e s s e l b a c h ~ s t u d y . ~}$

$\star \star$ Brain only; excludes the rest of the nervous system.

†TThe expected value for a subgroup of this category was estimated by assuming proportionality between brain-cancer and total cancer expected values for the subgroup as compared with the other groups. 
Table 11 Risk of non-Hodgkin's lymphoma by latency

\begin{tabular}{|c|c|c|c|c|}
\hline \multirow[b]{2}{*}{ Study } & & \multicolumn{3}{|l|}{ Latency $(y)$} \\
\hline & & $S M R(O / E)$ & $S M R(O / E)$ & $S M R(O / E)$ \\
\hline 8 & & $\begin{array}{l}0-9 y \\
0(0 / 0.51)\end{array}$ & $\begin{array}{l}10-19 y \\
1.0(1 / 0.96)\end{array}$ & $\begin{array}{l}\geqslant 20 y \\
0.4(1 / 2 \cdot 65)\end{array}$ \\
\hline $9 a$ & Steenland et al ${ }^{14}$ & $\begin{array}{l}0-9 y \\
1.3(5 / 3.83)\end{array}$ & $\begin{array}{l}10-20 y \\
0.9(5 / 5 \cdot 32)\end{array}$ & $\begin{array}{l}\geqslant 20 y \\
1.7(6 / 3.51)\end{array}$ \\
\hline 11 & Bisanti et al ${ }^{18} \dagger$ & $\begin{array}{l}0.9 y \\
7 \cdot 1(3 / \sim 0.42)\end{array}$ & $\begin{array}{l}10-19 y \\
2.9(1 / \sim 0.34)\end{array}$ & $\begin{array}{l}\geqslant 20 y \\
0(0 / \sim 0 \cdot 21)\end{array}$ \\
\hline \multicolumn{2}{|c|}{ Combined } & $\begin{array}{l}0-9 y \\
1 \cdot 7(8 / 4 \cdot 76)\end{array}$ & $\begin{array}{l}10-19 y \\
1 \cdot 1(7 / 6.62)\end{array}$ & $\begin{array}{l}\geqslant 20 y \\
1 \cdot 1(7 / 6 \cdot 37)\end{array}$ \\
\hline
\end{tabular}

*Expected values estimated by assuming that non-Hodgkin's lymphoma constitutes 69\% of the ICD-9 codes 200, 202, 203, 208 (based on United States white male mortality rates, ages $20-74^{46}$ ).

†Bisanti et al ${ }^{18}$ provided an expected value based on only ICD-9 diagnostic code 200, rather than codes 200 and 202 . From the Connecticut Cancer Registry ${ }^{38}$ (white males, ages 20-74) we estimated that code 202 was $65 \%$ as frequent as code 200 and incremented the expected value by $65 \%$.

random series of non-leukaemic haematopoietic malignancies among men, ages $20-74$.

Nevertheless, the available EtO studies suggest there may be a risk for non-Hodgkin's lymphomas. Table 8 and fig 2 summarise the overall findings for the 31 cases of non-Hodgkin's lymphomas. The summary SMR is 1.35 with a $95 \%$ CI of $0.93-1.90$ $(p=0 \cdot 10)$. The $\chi^{2}$ test for heterogeneity was not significant $(p=0.36)$.

In only three studies was enough information available to examine the risk of non-Hodgkin's lymphomas according to frequency or intensity of EtO exposure. The data in table 9 do not indicate a trend for any individual study or the combined studies. Table 10 shows the data for nonHodgkin's lymphomas according to duration of exposure; none of the five studies gives clear evidence of a trend. Similarly, there are no trends by interval since first EtO exposure (table 11).

Stayner et al ${ }^{15}$ however, recently reported new analyses of the data of Steenland et al ${ }^{14}$ based on a measure of cumulative exposure (duration $\times$ intensity), which is the preferred exposure metric. ${ }^{37}$ The estimates of cumulative exposures for subjects were derived from a regression equation that included variables predictive of exposure levels. ${ }^{28}$ The SMRs for cumulative exposure levels were 1.17 for $<1200 \mathrm{ppm}$-days, 0.96 for $1200-8500$ ppm-days and 1.92 for $>8500$ ppm-days. An exposure-response analysis, with cumulative exposure as a continuous variable, showed a trend in risk of non-Hodgkin's lymphomas with exposure $(p=0.05)$ with a 10 year exposure lag. Although the greatest overall excess in haematopoietic cancers was in the study of Steenland et $a l^{14}$ after a latency of 20 years, there was no evidence that the exposure-response trend increased at long latencies for any of the types of haematopoietic cancers.

Because lymphocytic leukaemia is biologically similar to non-Hodgkin's lymphomas, Stayner et al ${ }^{15}$ combined the two groups under the rubric "lymphoid cancer." An exposure-response analysis of lymphoid cancer showed a significant positive trend $(p=0.004)$ when a five year exposure lag was applied to the person-years analysis.

In evaluating these results, it should be noted that they reported the results for the exposure lag (five, 10 , or 20 years) that yielded the largest $\chi^{2}$ value; this procedure capitalises on chance to some degree. Secondly, Stayner et al ${ }^{15}$ noted that the exposure-response results were based on small numbers and were therefore not very robust; for? example, deleting the single case with the highest exposure changed the lymphoid cancer results from $p=0.004$ to $p=0.09$, although the magnitude of the risk coefficient changed little. Thirdly, the positive exposure-response relation was confined to men; the fact that none was seen among women argues for caution in interpreting the results. Nevertheless, the quantitative association between exposure to EtO and non-Hodgkin's lymphomas or lymphoid cancer is an important finding that merits close scrutiny in this and other studies. Because of its limitations, however, the analysis requires other supportive evidence before it can be concluded that there is a causal relation.

\section{STOMACH CANCER}

Another cancer that has been tentatively linked to EtO exposure, both in animals and humans, is stomach cancer, based initially on Hogstedt's (study No 2) findings $(\mathrm{O} / \mathrm{E}=4 / 0 \cdot 8)$ among the production workers at a plant which used the chlorohydrin process for producing EtO. ${ }^{5}$ Although this original observation could have been due to chance, extended follow up of the same workers replicated an elevated rate $(\mathrm{O} / \mathrm{E}=5 / 0 \cdot 4)$. Three other studies also showed non-significant elevations in stomach cancer mortality-those by Hogstedt No 3, Teta et $a l^{13}$ and Kiesselbach et al ${ }^{10}$ (which 
Table 12 Stomach cancer among exposed workers: ratios of observed to expected cancers and confidence intervals (CI), by individual study and overall meta-analysis

\begin{tabular}{|c|c|c|c|c|c|}
\hline \multicolumn{2}{|c|}{ Study } & $\frac{\text { Observed }(O)}{1}$ & $\begin{array}{l}\text { Expected (E) } \\
?\end{array}$ & \multicolumn{2}{|c|}{ O/E ratio $(95 \% C I)$} \\
\hline $\begin{array}{l}1 \\
2 \\
1,3 \\
4 \\
5 \\
6 \\
7 \\
8 \\
8 \\
9 \mathrm{a} \\
9 \mathrm{~b} \\
10 \\
11\end{array}$ & 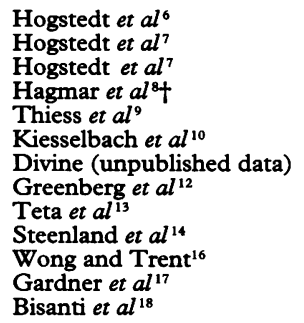 & $\begin{array}{r}1 \\
9 \\
1 \\
0 \\
4 \\
14 \\
0 \\
3 \\
8 \\
11 \\
15 \\
5 \S \\
5\end{array}$ & $\begin{array}{l}? \\
1 \cdot 27 \\
0 \cdot 53 \\
0 \cdot 5 \\
2 \cdot 67 \\
10 \cdot 15 \\
\sim 0 \cdot 91 \ddagger \\
3 \cdot 7 \\
5 \cdot 00 \\
11 \cdot 58 \\
15 \cdot 42 \\
6 \cdot 68 \S \\
4 \cdot 10\end{array}$ & $\begin{array}{l}\overline{7 \cdot 1^{\star}} \\
1 \cdot 9^{\star} \\
0 \cdot 0^{\star} \\
1 \cdot 5^{\star} \\
1 \cdot 4^{\star} \\
0 \cdot 0^{\star} \\
0 \cdot 8^{\star} \\
1 \cdot 6^{\star} \\
0 \cdot 9^{\star} \\
1 \cdot 0^{\star} \\
0 \cdot 7^{\star} \\
1 \cdot 2^{\star}\end{array}$ & $\begin{array}{l}(-) \\
(3 \cdot 5-13 \cdot 0) \\
(0 \cdot 1-9 \cdot 3) \\
(0 \cdot 0-6 \cdot 0) \\
(0 \cdot 5-3 \cdot 6) \\
(0 \cdot 8-2 \cdot 3) \\
(0 \cdot 0-3 \cdot 5) \\
(0 \cdot 2-2 \cdot 2) \\
(0 \cdot 7-3 \cdot 0) \\
(0 \cdot 5-1 \cdot 7) \\
(0 \cdot 6-1 \cdot 6) \\
(0 \cdot 3-1 \cdot 7) \\
(0 \cdot 4-2 \cdot 7)\end{array}$ \\
\hline \multicolumn{2}{|c|}{$\begin{array}{l}\text { Meta-analysis } \\
\text { Including heterogeneity }\end{array}$} & 57 & $44 \cdot 56$ & $1 \cdot 28$ & $\begin{array}{l}(0 \cdot 98-1 \cdot 65) \\
(0 \cdot 72-2 \cdot 26)\end{array}$ \\
\hline
\end{tabular}

*These studies were included in the meta-analysis.

tIndicates a tally of incident cases; otherwise mortality was assessed.

\#xpected value estimated by assuming that stomach cancer constitutes $12.8 \%$ of total digestive cancer mortality (based on United States white male rates, ages $20-74^{46}$ ).

§Includes unpublished update of mortality.

includes the Thiess study. Table 12 and fig 3 summarise the findings for stomach cancer and show that, for all but the Hogstedt study, the SMRs and their confidence intervals overlap. The summary SMR is 1.28 with a $95 \%$ confidence interval of $0.98-1 \cdot 65$. Hogstedt's study No 2 is alone responsible for the lack of homogeneity among the tested relative risks $(p<0.0001)$. The approximate $95 \%$ confidence interval, taking into account the heterogeneity in risk estimates, is $0 \cdot 73-2 \cdot 26$. If Hogstedt's study No 2 is excluded, the summary SMR is 1.11 and the test for heterogeneity is nonsignificant $(p=0.67)$.

A closer examination of these data does not support a causal relationship. Analyses of stomach cancer risk by frequency/intensity of exposure

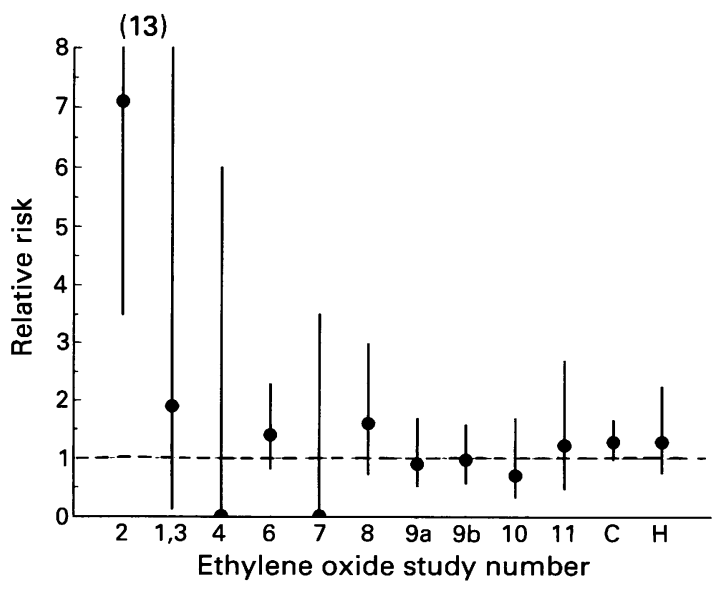

Figure 3 Stomach cancer: SMRs and 95\% confidence intervals among EtO exposed workers, for individual studies and the combined studies. (table 13) provide no evidence of a trend overall or for any study but Hogstedt's. Similarly, there is no evidence for a gradient in risk by duration of exposure (table 10) or by latency (table 14). In Stayner's ${ }^{15}$ analysis by cumulative exposure, the trend was statistically significant in the negative direction.

Hogstedt's study, that showed a statistically significant elevation in stomach cancer (table 12), was at a plant that produced EtO by the chlorohydrin process and additionally produced ethylene chlorohydrin in the same area. Hogstedt's excess of stomach cancer may have been related to the fact that, in the earlier years, the workers tasted the chemical reaction product to assess the result of the EtO synthesis. The EtO reaction mixture "would have contained EtO, ethylene glycol, ethylene chlorohydrin, ethylene dichloride, bis-chloroethyl ether, and other substances." 12 There is a report that rats gavaged with $\mathrm{EtO}^{40}$ develop cancer of the forestomach, and also evidence of animal carcinogenicity for ethylene dichloride and bis-chloroethyl ether. ${ }^{12} \mathrm{~A}$ list of the variety of chemicals produced or used at this plant is shown in table 3.

In summary, the most likely explanation for the one positive finding is that some other chemical(s) in the plant environment, or possibly the direct ingestion of EtO by workers at that plant, caused the excess. The weight of current evidence does not indicate that airborne EtO causes human stomach cancer.

\section{BRAIN AND NERVOUS SYSTEM CANCER}

Since a study of EtO exposure in rats found an increased incidence of gliomas of the brain, ${ }^{3}$ this site is of interest. Table 15 and fig 4 summarise the findings for brain and nervous system cancer (here- 
Table 13 Stomach cancer risks by intensity or frequency of exposure

\begin{tabular}{|c|c|c|c|c|}
\hline \multirow{2}{*}{\multicolumn{2}{|c|}{ Study }} & \multicolumn{3}{|c|}{ Intensity or frequency of exposure } \\
\hline & & \multirow[t]{2}{*}{ Low SMR (O/E) } & \multirow{2}{*}{$\begin{array}{l}\text { Intermediate SMR }(O / E) \\
\text { Maintenance } \\
\text { workers } \\
2 \cdot 5(1 / 0 \cdot 4)\end{array}$} & \multirow{2}{*}{$\begin{array}{l}\text { High SMR }(O / E) \\
\text { Exposed } \\
\text { full-time } \\
7 \cdot 5(3 / 0 \cdot 4)\end{array}$} \\
\hline 2 & Hogsted et $a^{5}$ & & & \\
\hline 6 & Kiesselbach et al ${ }^{10}$ & $\begin{array}{l}\text { Weak } \\
1 \cdot 5(4 / 2 \cdot 62)\end{array}$ & $\begin{array}{l}\text { Medium } \\
1 \cdot 7(5 / 3 \cdot 01)\end{array}$ & $\begin{array}{l}\text { High } \\
0(0 / 0 \cdot 08)\end{array}$ \\
\hline 8 & Teta et al ${ }^{13}$ & $\begin{array}{l}\operatorname{Low}^{\star} \\
2 \cdot 2(4 / 1 \cdot 78)\end{array}$ & $\begin{array}{l}\text { Intermediate } \\
3.7(4 / 1 \cdot 07)\end{array}$ & $\begin{array}{l}H^{\prime i g h}{ }^{\star} \\
0.8(1 / 1 \cdot 24)\end{array}$ \\
\hline $9 a$ & Steenland et al ${ }^{14}$ & $\begin{array}{l}\text { Warehouse } \\
0 \cdot 8(1 / 1 \cdot 30)\end{array}$ & $\begin{array}{l}\text { Steriliser } \\
\text { area or } \\
\text { maintenance† } \\
0.9(3 / 3 \cdot 21)\end{array}$ & $\begin{array}{l}\text { Steriliser or } \\
\text { production } \\
\text { operator } \ddagger \\
0.9(9 / 10.0)\end{array}$ \\
\hline 10 & Gardner et al ${ }^{17}$ & $\begin{array}{l}\text { Unknown } \\
0(0 / 1 \cdot 15)\end{array}$ & $\begin{array}{l}\text { Possible } \\
0(0 / 1 \cdot 02)\end{array}$ & $\begin{array}{l}\text { Definite } \\
1 \cdot 3(5 / 3 \cdot 78)\end{array}$ \\
\hline & ombined§ & $\begin{array}{l}\text { Low } \\
1 \cdot 6(9 / 5 \cdot 70)\end{array}$ & $\begin{array}{l}\text { Intermediate } \\
1 \cdot 5(13 / 8 \cdot 71)\end{array}$ & $\begin{array}{l}\text { High } \\
1 \cdot 2(18 / 15 \cdot 50)\end{array}$ \\
\hline
\end{tabular}

*Assigned for $\geqslant 2$ years to a high (/intermediate/low) department.

tThose who worked intermittently in the steriliser area.

¥The expected value for a subgroup was estimated by assuming proportionality between stomach-cancer and total-cancer expected values for the subgroup compared with the combined other groups.

$\S$ Excludes the "unknown" category in the Gardner study.

after referred to as "brain cancer"). The results shown in table 15 give some suggestion of an elevated risk in three out of the seven studies from which information on brain cancer can be derived. However, none of the findings is significant, and the largest study yielded a relative risk of only 0.6 .

Findings for brain cancer were not available or derivable from two of the studies by Hogstedt et al and those by Kiesselbach et $a l^{10}$ and Gardner et $\mathrm{al}^{17}$; the most likely explanation is that there were either no cases or no excess of cases, so it was not reported. For two other studies (by Hogstedt et al and Bisanti et al ${ }^{18}$ ) brain cancer was not reported, but it could be deduced that none had occurred, and approximate expected values were derived for them by indirect means (table 15). The numbers of expected cases were small except in the cohort of Steenland $e t a l^{14}$ and Wong and Trent. ${ }^{16}$ The summary SMR was 0.89 with a $95 \%$ CI of $0 \cdot 55-1 \cdot 36$. However, there was substantial evi dence of heterogeneity among the SMR estimateso $(p=0.003)$. No one study contributed all the het-? erogeneity, although the largest contribution came from the Thiess study ( $p=0.13$ with it excluded). The approximate $95 \%$ confidence interval, taking into account the heterogeneity in risk estimates, is $0 \cdot 39-2 \cdot 04$.

Only three studies have presented analyses of brain cancer by frequency/intensity of exposure, and in these studies there was no indication of a

Table 14 Stomach cancer risk by latency (interval since first exposure to EtO)

\begin{tabular}{|c|c|c|c|c|}
\hline \multirow[b]{2}{*}{ Study } & & \multicolumn{3}{|l|}{ Latency $(y)$} \\
\hline & & $S M R(O / E)$ & $S M R(O / E)$ & $S M R(O / E)$ \\
\hline 2 & Hogstedt et $a l^{5}$ & & $\begin{array}{l}10-19+y^{*} \\
5 \cdot 4(2 / 0 \cdot 37)\end{array}$ & $\begin{array}{l}\geqslant 20 y \dagger \\
4.7(2 / 0.43)\end{array}$ \\
\hline 6 & Kiesselbach et al ${ }^{10}$ & $\begin{array}{l}<10 y \\
1 \cdot 2(3 / 2 \cdot 49)\end{array}$ & $\begin{array}{l}10-19 y \\
1 \cdot 4(5 / 3 \cdot 57)\end{array}$ & $\begin{array}{l}\geqslant 20 y \\
1.5(6 / 4 \cdot 10)\end{array}$ \\
\hline 8 & Teta et al ${ }^{13}$ & $\begin{array}{l}0-9 y \\
0(0 / 0 \cdot 65)\end{array}$ & $\begin{array}{l}10-19 y \\
2 \cdot 4(3 / 1 \cdot 23)\end{array}$ & $\begin{array}{l}\geqslant 20 y \\
1.6(5 / 3 \cdot 14)\end{array}$ \\
\hline $9 a$ & Steenland et al ${ }^{14}$ & $\begin{array}{l}<10 y \\
0.8(3 / 3 \cdot 75)\end{array}$ & $\begin{array}{l}10-20 y \\
1.0(5 / 5.05)\end{array}$ & $\begin{array}{l}>20 y \\
1.1(3 / 2.83)\end{array}$ \\
\hline \multirow[t]{2}{*}{11} & Bisanti et al ${ }^{18}$ & $\begin{array}{l}<10 y \\
2 \cdot 5(3 / 1 \cdot 21)\end{array}$ & $\begin{array}{l}10-19 y \\
1 \cdot 3(2 / 1 \cdot 52)\end{array}$ & $\begin{array}{l}\geqslant 20 y \\
0(0 / 1 \cdot 37)\end{array}$ \\
\hline & & $\begin{array}{l}\text { Brief } \\
1 \cdot 1(9 / 8 \cdot 10)\end{array}$ & $\begin{array}{l}\text { Intermediate } \\
1.4(17 / 11 \cdot 74)\end{array}$ & $\begin{array}{l}\text { Long } \\
1 \cdot 3(16 / 11 \cdot 87)\end{array}$ \\
\hline
\end{tabular}

*Includes experience for 10-19 years latency period for all workers with $1+$ year of exposure and $20+$ years latency period for worker with 1-9 years of exposure.

tIncludes only those with $10+$ years of exposure. 
Table 15 Brain and nervous system cancer among exposed workers: ratios of observed to expected cancers and confidence intervals (CI), by individual study and overall meta-analysis

\begin{tabular}{|c|c|c|c|c|c|}
\hline \multicolumn{2}{|c|}{ Study } & \multirow{2}{*}{$\frac{\text { Observed }(O)}{0}$} & \multirow{2}{*}{$\frac{\text { Expected (E) }}{-0.32^{\star}}$} & \multicolumn{2}{|c|}{ O/E ratio $95 \%(C I)$} \\
\hline 2 & Hogstedt et al ${ }^{5}$ & & & $0.0 \dagger$ & $(0 \cdot 0-9 \cdot 4)$ \\
\hline 4 & Hagmar et $a l^{8} \ddagger$ & 1 & $1 \cdot 31$ & $0.8 \dagger$ & $(0 \cdot 1-3 \cdot 8)$ \\
\hline 5 & Thiess $e t a l^{\circ} \ddagger$ & 1 & 0.08 & $12 \cdot 7 \dagger$ & $(0 \cdot 6-62 \cdot 9)$ \\
\hline 7 & Divine (unpublished data) & 3 & $1 \cdot 08$ & $2 \cdot 8 \dagger$ & $(0 \cdot 7-7 \cdot 6)$ \\
\hline 8 & Teta et al ${ }^{13}$ & 6 & $4 \cdot 00$ & $1.5 \dagger$ & $(0 \cdot 6-3 \cdot 1)$ \\
\hline $9 \mathbf{a}$ & Steenland et al ${ }^{14}$ & 6 & $11 \cdot 6$ & 0.5 & $(0 \cdot 2-1 \cdot 1)$ \\
\hline $9 b$ & Wong and Trent ${ }^{16}$ & 8 & $14 \cdot 27$ & $0.6 \dagger$ & $(0 \cdot 3-1 \cdot 1)$ \\
\hline 11 & Bisanti et al ${ }^{18}$ & 0 & $-1.38 \S$ & $0.0 \dagger$ & $(0.0-7.9)$ \\
\hline \multicolumn{2}{|c|}{$\begin{array}{l}\text { Meta-analysis } \\
\text { Including heterogeneity }\end{array}$} & 19 & $21 \cdot 44$ & 0.89 & $\begin{array}{l}(0.55-1.36) \\
(0.39-2.04)\end{array}$ \\
\hline
\end{tabular}

^Expected value estimated by assuming brain-CNS cancer rates were $117 \%$ as great as those for total leukaemia. This is a reasonable assumption, because, for males in the Swedish cancer registry, ${ }^{38}$ the regression slopes of the rates by age (ages 20-74) were similar for CNS cancers and leukaemia.

†These studies were included in the meta-analysis.

Brain only; excludes the rest the nervous system.

Expected value estimated by assuming brain-CNS cancer rates were $16 \%$ as great as those for all haematopoietic cancers. This is a reasonable assumption, because, in the Lombardy cancer registry, ${ }^{38}$ the regression slopes of the rates by age (ages $20-74$ ) were similar for CNS cancers and haematopoietic cancers.

positive trend (table 16). The four studies providing information on brain cancer by duration of exposure (table 10) did not indicate a statistically significant gradient of risk by duration of exposure $(\mathrm{p}=0 \cdot 24)$. The three studies presenting data by latency showed a suggestive combined trend $(\mathrm{p}=$ 0.07 ; table 17). When the large cohort of Steenland et $a l^{14}$ was analysed by cumulative exposure, the trend was in the negative direction. ${ }^{15}$

In summary, none of the seven studies showed a statistically significant excess of brain cancer. The overall meta-analysis yielded no evidence for an elevation of brain-cancer risk, nor did the analyses by intensity of exposure or cumulative exposure. There was a weak suggestion of a trend by latency in the report of Steenland et al ${ }^{14}$. Overall, the

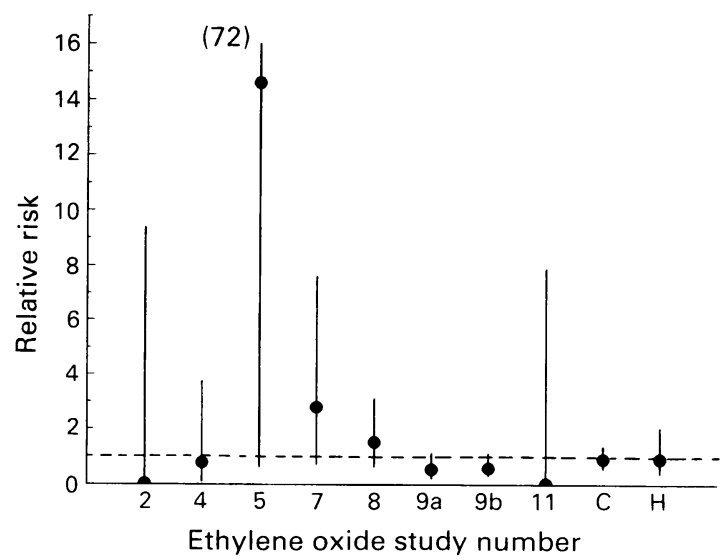

Figure 4 Brain and nervous system cancer: SMRs and $95 \%$ confidence intervals among EtO exposed workers, for individual studies and the combined studies. weight of evidence indicates no association between EtO exposure and brain cancer.

\section{PANCREATIC CANCER}

Table 18 and fig 5 summarise the findings for pancreatic cancer. The summary SMR for pancreatic cancer was 0.98 , based on 34 deaths, with a $95 \%$ CI of $0.69-1 \cdot 36$. The $\chi^{2}$ test for heterogeneity of the risk estimate was not significant $(p=0.41)$. The confidence intervals for the studies are quite overlapping (fig 5).

Analyses of the risk of pancreatic cancer according to intensity and frequency of exposure (table 16) did not indicate a trend. For duration of exposure, there was some indication of a positive trend in the studies of Divine and Bisanti et al ${ }^{18}$, but the gradients were not positive in the other two studies, and the combined data showed no trend (table 10). The relative risk of pancreatic cancer did not vary consistently by latency (table 17). The analysis by Stayner $e t a l^{15}$ of cumulative EtO exposure showed no trend.

The first to report on pancreatic cancer were Morgan et al ${ }^{11}$ with three deaths compared to $0 \cdot 8$ expected; in the update to this study by Divine the expected number was increased to 1.5 and no additional deaths occurred. These data were examined by calendar time of employment; all the pancreatic cancer cases occurred among those employed prior to 1959 when only the chlorohydrin process of EtO production was used. Greenberg et al ${ }^{12}$ also found a suggestive excess of pancreatic cancer, with seven observed and $4 \cdot 1$ expected. An examination of the work histories of their cases showed that nearly all had worked in a department that produced ethylene chlorohydrin but not EtO, and that had little EtO exposure. If those workers are removed, then $\mathrm{O} / \mathrm{E}=1 / 3 \cdot 4$. The subsequent follow up of this 
Table 16 Risk of brain and nervous system cancer or pancreatic cancer by intensity or frequency of exposure

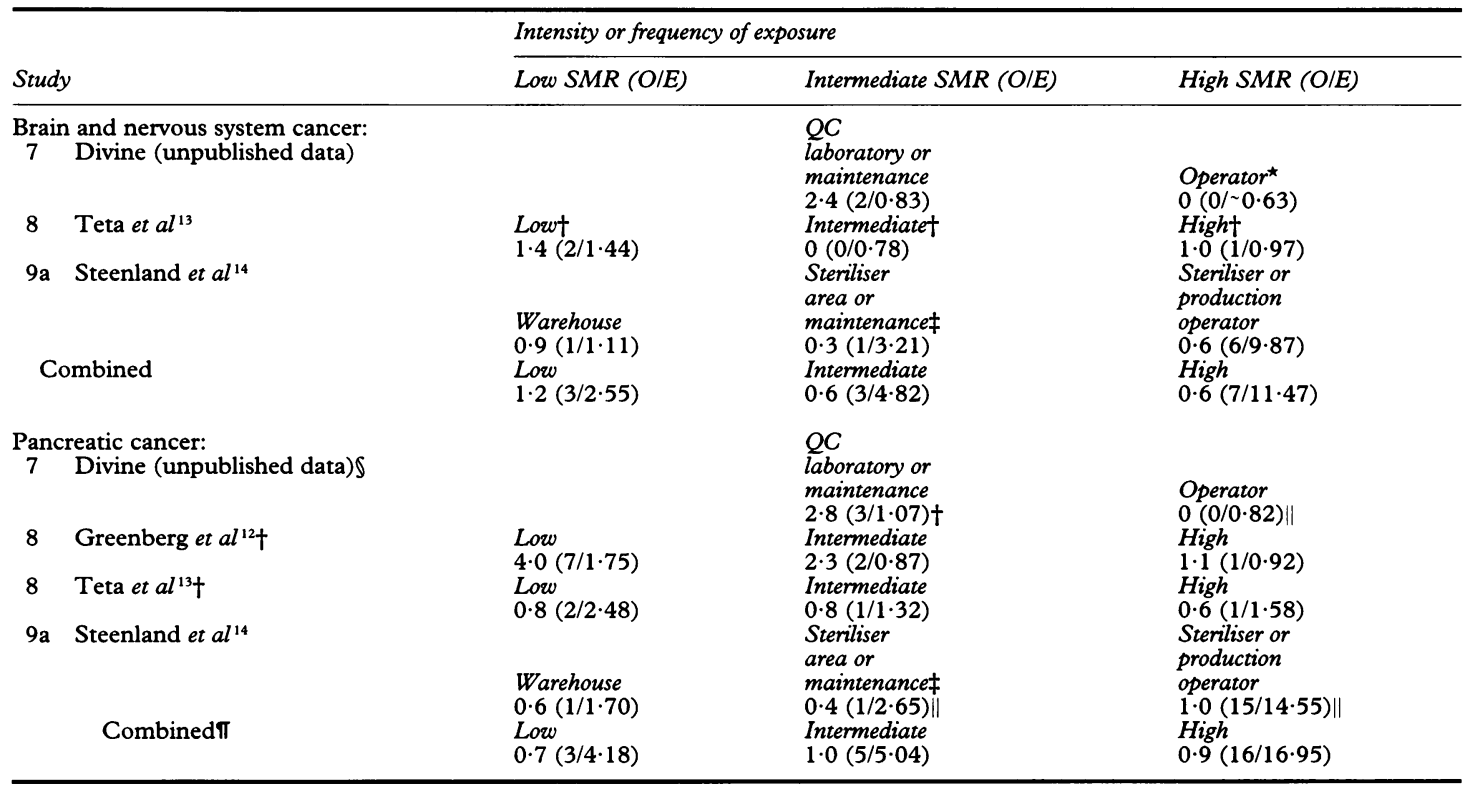

*The expected value for a subgroup was estimated by assuming proportionality between brain cancer and total-cancer expected values for the subgroup as compared with the combined other groups.

†Assigned for $\geqslant 2$ years to a high (/intermediate/low) department.

$¥$ Those who worked intermittently in the steriliser area.

$\S$ These three worker categories are not mutually exclusive; some workers are in multiple categories.

$\|$ Expected value for this group (or part of it) was estimated by assuming proportionality between pancreatic total-cancer and total-cance

expected values for this group as compared with the total cohort.
TExcludes the study by Greenberg, since Teta provides an update of the study, and the Greenberg study included a department that had exposure to other chemicals that apparently cause pancreatic cancer.

cohort by Teta $e a^{13}$, without the ethylene chlorohydrin production workers, continued to show a (non-significant) deficit of pancreatic cancer among EtO exposed workers (table 18).

In summary, closer examination and further follow up of the only two studies that initially suggested an association between EtO and pancreatic cancer, have not supported the association; in one of these studies the evidence pointed to confounding by another chemical exposure as the probable source of the elevated risk. The overall SMR was not elevated, nor did the analyses by exposure intensity or duration support an association. The human data thus provide no evidence that EtO causes pancreatic cancer.

\section{ALL CANCERS}

Table 19 summarises the findings for all malignant neoplasms. The summary SMR was 0.94 with a $95 \%$ CI of $0 \cdot 88-1 \cdot 01$. The Hogstedt studies have the highest relative risks, and they made the largest contributions to the heterogeneity of risks $(p=0.004)$. The results for Hogstedt's study No 2 was dependent on the excesses of stomach can- cers and leukaemia-for all other cancers combined the observed number of deaths in this study was eight compared to 10.3 expected (SMR = $0 \cdot 78,95 \%$ confidence interval $0 \cdot 34-1 \cdot 53$ ). For the remaining studies the confidence intervals are quite overlapping. The $95 \% \mathrm{CI}$, taking heterogeneity of risks into account, was $0 \cdot 84-1 \cdot 06$. Only the three Hogstedt studies showed SMRs nominally greater than one for all cancers, which was entirely accounted for by the previously mentioned excesses of leukaemia and stomach cancer.

In summary, only one of the 10 studies showed a significant excess, but this was in a plant where many chemicals were used. ${ }^{7}$ Overall, there was no evidence of an excess of total cancer among EtO exposed workers.

\section{DEATHS OTHER THAN CANCER}

Table 20 summarises the findings for mortality due to heart disease. The summary SMR is 0.73 with a $95 \%$ confidence interval of $0.67-0.79$ (or 0.63 0.84 , including heterogeneity). Only Hogstedt's study No 2, based on fairly small numbers, 
Table 17 Brain and nervous system cancer or pancreatic cancer risk by latency (interval since first exposure to EtO)

\begin{tabular}{|c|c|c|c|c|}
\hline \multirow[b]{2}{*}{ Study } & & \multicolumn{3}{|c|}{ Latency (years) } \\
\hline & & $S M R(O / E)$ & $S M R(O / E)$ & $S M R(O / E)$ \\
\hline $\begin{array}{l}\text { Brair } \\
7\end{array}$ & $\begin{array}{l}\text { and nervous system cancer } \\
\text { Divine (unpublished data) }\end{array}$ & $\begin{array}{l}<10 y \\
0(0 / 0 \cdot 17)\end{array}$ & $\begin{array}{l}10-19 y \\
5 \cdot 3(2 / 0 \cdot 38)\end{array}$ & $\begin{array}{l}20+y \\
1.9(1 / 0.53)\end{array}$ \\
\hline 8 & Teta et al ${ }^{13}$ & $\begin{array}{l}0-9 y \\
1 \cdot 4(1 / 0 \cdot 72)\end{array}$ & $\begin{array}{l}10-19 y \\
0 \cdot 9(1 / 1 \cdot 13)\end{array}$ & $\begin{array}{l}20+y \\
1 \cdot 9(4 / 2 \cdot 15)\end{array}$ \\
\hline & Steenland $e t a l^{14}$ & $\begin{array}{l}<10 y \\
0 \cdot 4(2 / 4.55)\end{array}$ & $\begin{array}{l}10-20 y \\
0 \cdot 2(1 / 5 \cdot 26)\end{array}$ & $\begin{array}{l}>20 y \\
1 \cdot 4(3 / 2 \cdot 16)\end{array}$ \\
\hline & Combined & $\begin{array}{l}\text { Brief } \\
0.6(3 / 5 \cdot 44)\end{array}$ & $\begin{array}{l}\text { Intermediate } \\
0 \cdot 6(4 / 6 \cdot 77)\end{array}$ & $\begin{array}{l}\text { Long } \\
1 \cdot 7(8 / 4 \cdot 84)\end{array}$ \\
\hline $\begin{array}{l}\text { Panc } \\
7\end{array}$ & $\begin{array}{l}\text { reatic cancer: } \\
\text { Divine (unpublished data) }\end{array}$ & & $\begin{array}{l}<26 y \\
0(0 / 0 \cdot 18)\end{array}$ & $\begin{array}{l}26+y \\
2 \cdot 3(3 / 1 \cdot 31)\end{array}$ \\
\hline 8 & Teta et al ${ }^{13}$ & $\begin{array}{l}0-9 y \\
0(0 / 0 \cdot 70)\end{array}$ & $\begin{array}{l}10-19 y \\
0 \cdot 7(1 / 1 \cdot 54)\end{array}$ & $\begin{array}{l}20+y \\
0 \cdot 7(3 / 4 \cdot 34)\end{array}$ \\
\hline & $\begin{array}{l}\text { Steenland } \text { et } a l^{14} \\
\text { Bisanti } \text { et } a l^{18}\end{array}$ & $\begin{array}{l}<10 y \\
1 \cdot 3(6 / 4 \cdot 58) \\
0-9 y \\
0(0 / 0 \cdot 36)\end{array}$ & $\begin{array}{l}10-20 y \\
0 \cdot 8(6 / 7 \cdot 79) \\
10-19 y \\
2 \cdot 2(1 / 0 \cdot 45)\end{array}$ & $\begin{array}{l}>20 y \\
0 \cdot 9(4 / 4 \cdot 65) \\
20+y \\
5 \cdot 3(2 / 0 \cdot 37)\end{array}$ \\
\hline & Combined & $\begin{array}{l}\text { Brief } \\
1 \cdot 1(6 / 5 \cdot 64)\end{array}$ & $\begin{array}{l}\text { Intermediate } \\
0.8(8 / 9.96)\end{array}$ & $\begin{array}{l}\text { Long } \\
1 \cdot 1(12 / 10 \cdot 67)\end{array}$ \\
\hline
\end{tabular}

reported a relative risk greater than unity. Table 20 also shows the summary findings for cerebrovascular disease mortality. The summary SMR is 0.62 with a $95 \%$ confidence interval of $0.51-0.75$ (or $0.42-0.92$, including heterogeneity). Of the studies that have given results for this cause of death, only the Swedish studies, based on relatively small numbers, reported relative risks greater than unity. For all circulatory disease the summary SMR was 0.70 with a $95 \%$ CI of $0.65-0.76$ (or $0 \cdot 59-0 \cdot 84$, including heterogeneity). Hogstedt's study No 2 had the highest relative risk, based entirely on the earlier discussed increases in heart disease and cerebrovascular disease. In summary, none of the studies showed significant elevations for categories of circulatory disease, and most of the studies other than Hogstedt's had SMRs numerically less than one. Thus there is no material evidence for a risk of circulatory disease associated with EtO.

Table 20 summarises the findings for all causes of death. The summary SMR was 0.77 with a $95 \%$ confidence interval of $0.74-0.80$ (or $0.72-0.83$, including heterogeneity). The only study with a rel-

Table 18 Pancreatic cancer among exposed workers: ratios of observed to expected cancers and confidence intervals (CI) by individual study and overall meta-analysis

\begin{tabular}{|c|c|c|c|c|c|}
\hline \multicolumn{2}{|c|}{ Study } & \multirow{2}{*}{$\frac{\text { Observed }(O)}{0}$} & \multirow{2}{*}{$\begin{array}{l}\text { Expected (E) } \\
0.47^{\star}\end{array}$} & \multicolumn{2}{|c|}{ O/E ratio $(95 \% C I)$} \\
\hline 2 & Hogstedt et al 5 & & & $0.0 t$ & $(0.0-6 \cdot 4)$ \\
\hline 4 & Hagmar et al ${ }^{8}$ & 0 & $-0.30^{\star}$ & $0.0 t$ & $(0 \cdot 0-10 \cdot 0)$ \\
\hline 5 & Thiess et al ${ }^{9}$ & 0 & $-0.68 \ddagger$ & $0.0+$ & $(0 \cdot 0-4 \cdot 4)$ \\
\hline 6 & Morgan et al ${ }^{11}$ & 3 & $0.80^{\top}$ & $3 \cdot 8$ & $(1 \cdot 0-10 \cdot 2)$ \\
\hline 7 & Divine (unpublished data) & 3 & 1.49 & $2.0 t$ & $(0 \cdot 5-5 \cdot 5)$ \\
\hline 8 & Greenberg et al ${ }^{12}$ & $7 \S$ & $4.09 \S$ & $1 \cdot 7$ & $(0 \cdot 7-3 \cdot 4)$ \\
\hline 8 & Teta et al 13 & 4 & 6.57 & $0.6 t$ & $(0 \cdot 2-1 \cdot 5)$ \\
\hline $9 \mathbf{a}$ & Steenland et al ${ }^{14}$ & 16 & $16 \cdot 90$ & 0.9 & $(0.6-1.5)$ \\
\hline $9 b$ & Wong and Trent ${ }^{16}$ & 20 & $20 \cdot 69$ & $1 \cdot 0 \dagger$ & $(0.6-1.5)$ \\
\hline 10 & Gardner et al ${ }^{17}$ & 4 & $3 \cdot 19$ & $1.3 t$ & $(0.4-3 \cdot 0)$ \\
\hline 11 & Bisanti et al ${ }^{18}$ & 3 & $1 \cdot 18$ & $2.5 t$ & $(0.6-6 \cdot 9)$ \\
\hline \multicolumn{2}{|c|}{ Meta-analysis } & 34 & $34 \cdot 57$ & 0.98 & $(0 \cdot 69-1 \cdot 36)$ \\
\hline
\end{tabular}

${ }^{\star}$ Expected value estimated by assuming pancreatic cancer rates were $59 \%$ as great as those for stomach cancer. This is a reasonable assumption, because, in the Swedish cancer registry, ${ }^{38}$ the regression slopes of the rates by age (ages $20-74$ ) were similar for stomach cancer and pancreatic cancer.

These studies were included in the meta-analysis.

†xpected value not given; calculated from age-specific person-years ${ }^{9}$ and rates for Saarland, Germany. ${ }^{38}$

§Excluding the 6 observed and 0.7 expected pancreatic cancers among men who worked in a chlorohydrin producing department that had little EtO exposure, $\mathrm{O} / \mathrm{E}=1 / 3 \cdot 4$

|Includes unpublished update of mortality. 


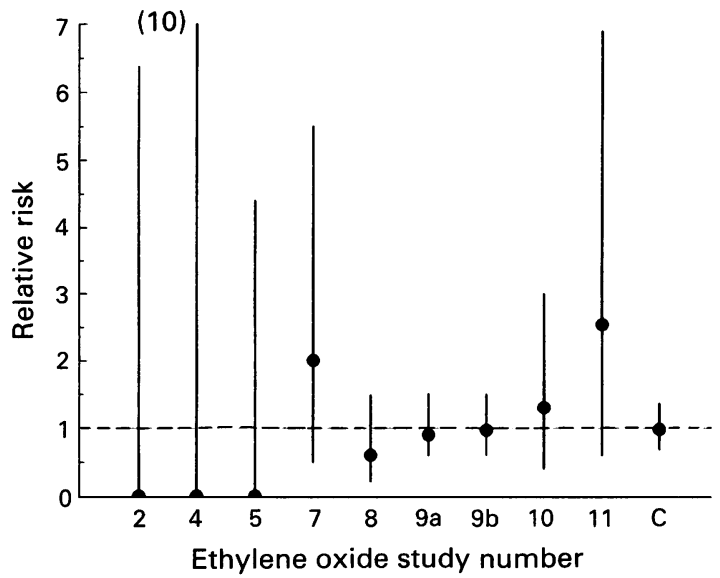

Figure 5 Pancreatic cancer: SMRs and 95\% confidence intervals among EtO-exposed workers, for individual studies and the combined studies.

ative risk suggestively greater than unity was Hogstedt's second study-this increase was highly dependent on the excesses from leukaemia and stomach cancer. In summary, when all causes of death was examined, no study showed a significant elevation in risk. The absence of an excess indicates that EtO has not had adverse effects upon overall mortality experience and life expectancy. The overall SMR of 0.77 is consistent with the magnitude of "healthy worker effect" typically found in occupational populations.

\section{EXAMINATION OF RISK BY SEX}

Few studies had substantial numbers of both male and female employees and fewer yet examined SMRs separately by sex. Hogstedt ${ }^{7}$ did not find a significant sex difference for haematopoietic cancers. The study by Steenland et al ${ }^{14}$ showed significant differences in the SMR by sex for all non-leukaemic haematopoietic cancers (male $\mathrm{O} / \mathrm{E}=19 / 10 \cdot 5$, female $=4 / 10 \cdot 2$ ), and for the successively narrower subcategories of non-Hodgkin's lymphoma $\quad($ male $=7 / 3 \cdot 2$, female $=1 / 3 \cdot 5)$ and lymphosarcoma-reticulosarcoma $\quad($ male $=7 / 2 \cdot 7$, female $=1 / 2 \cdot 6$ ). In all cases the SMR was elevated in males but was less than one in females, although there evidently was no major difference between the sexes in exposure magnitude. ${ }^{16}$ There were no sex differences in SMRs for leukaemia or multiple myeloma. In the replication and extension of this study by Wong and Trent, ${ }^{16}$ the overall male SMR for non-Hodgkin's lymphoma was significantly elevated, but the female SMR was less than unity. For all haematopoietic cancers there was a statistically significant deficit among women. Of particular interest is the fact that the cumulative exposureresponse trend for all haematopoietic malignancies in the analysis by Stayner et al ${ }^{15}$ was in the positive direction for men but in the negative direction for women. A test of the sex by exposure interaction was of borderline significance $(p=0.09)$. We suspect that the differences reported by Steenland et $a l,{ }^{14}$ Wong and Trent, ${ }^{16}$ and Stayner et al ${ }^{15}$ may represent chance findings among their numerous comparisons; if the differences are real, then the biological basis for them is unknown.

\section{PROBABILITIES OF EFFECTS}

While it has been conventional in epidemiological studies to present estimates of relative risk, such as SMRs, and their $95 \% \mathrm{CIs}$, it is informative to consider the whole range of probabilities in judging whether there may be a particular effect from an environmental exposure. ${ }^{41}$ One way of doing so is to plot a continuous function of confidence intervals ranging from $<1 \% \mathrm{CI}$ to $>99 \% \mathrm{CI}^{42}$

Figure 6 shows the overall confidence interval

Table 19 All cancer among exposed workers: ratios of observed to expected cancers and confidence intervals (CI), by individual study and overall meta-analysis

\begin{tabular}{|c|c|c|c|c|}
\hline \multicolumn{2}{|l|}{ Study } & $\frac{\text { Observed }(O)}{7}$ & $\begin{array}{c}\text { Expected (E) } \\
3.4 \\
11.90\end{array}$ & O/E ratio $(95 \% C I)$ \\
\hline $\begin{array}{l}1 \\
2 \\
1,3 \\
4 \\
5 \\
6 \\
7 \\
8 \\
9 \mathrm{a} \\
9 \mathrm{~b} \\
10 \\
11\end{array}$ & 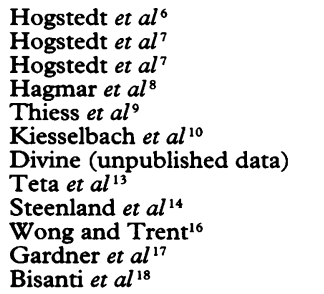 & $\begin{array}{r}7 \\
20 \\
13 \\
21 \\
12 \\
68 \\
19 \\
110 \\
343 \\
403 \\
85 \\
43\end{array}$ & $\begin{array}{c}3 \cdot 4 \\
11 \cdot 90 \\
7 \cdot 86 \\
26 \cdot 9 \\
15 \cdot 5 \\
69 \cdot 9 \\
28 \cdot 8 \\
128 \cdot 1 \\
380 \cdot 3 \\
446 \cdot 2 \\
76 \cdot 6 \\
33 \cdot 0\end{array}$ & $\begin{array}{l}2 \cdot 1^{\star}(0 \cdot 9-4 \cdot 1) \\
1 \cdot 7^{\star}(1 \cdot 1-2 \cdot 6) \\
1 \cdot 7^{\star}(0 \cdot 9-2 \cdot 8) \\
0 \cdot 8^{\star}(0 \cdot 5-1 \cdot 2) \\
0 \cdot 8^{\star}(0 \cdot 4-1 \cdot 3) \\
1 \cdot 0^{\star}(0 \cdot 8-1 \cdot 2) \\
0 \cdot 7^{\star}(0 \cdot 4-1 \cdot 0) \\
0 \cdot 9^{\star}(0 \cdot 7-1 \cdot 0) \\
0 \cdot 9^{\star}(0 \cdot 8-1 \cdot 0) \\
0 \cdot 9^{\star}(0 \cdot 8-1 \cdot 0) \\
1 \cdot 1^{\star}(0 \cdot 9-1 \cdot 4) \\
1 \cdot 3^{2}(1 \cdot 0-1 \cdot 7)\end{array}$ \\
\hline & $\begin{array}{l}\text { Meta-analysis } \\
\text { including heterogeneity }\end{array}$ & 782 & $829 \cdot 29$ & $\begin{array}{r}0.94(0.88-1.01) \\
(0.84-1.06)\end{array}$ \\
\hline
\end{tabular}

^These studies were included in the meta-analysis. 
Table 20 Meta-analyses of circulatory disease deaths and total mortality: overall ratios of observed to expected deaths among exposed workers, and confidence intervals (CI), with and without taking account of heterogeneity of risk

\begin{tabular}{lcclll}
\hline Cause of death & Observed $(O)$ & Expected $(E)$ & O/E Ratio & $95 \%$ CI for O/E & $95 \%$ CI with heterog. \\
\hline Heart disease & 645 & 884.2 & 0.73 & $0.67,0.79$ & $0.63,0.84$ \\
Cerebrovascular disease & 114 & 183.4 & 0.62 & $0.51,0 \cdot 75$ & $0.42,0 \cdot 92$ \\
All circulatory disease & 696 & 991.9 & 0.70 & $0.65,0 \cdot 76$ & $0.59,0 \cdot 84$ \\
All causes of death & 2540 & 3290.8 & 0.77 & $0.74,0.80$ & $0.72,0.83$ \\
\hline
\end{tabular}

Note: Not all studies had all three groupings of circulatory diseases. These tabulations include the report by Wong, but exclude Steenland's report.

function for the meta-analysis of the leukaemia data. The lower limit of the CI function equals one for approximately a $25 \%$ confidence interval; this corresponds to the calculation that the two-tailed p-value for the SMR is 0.74 , which is far from statistical significance. We can also ask what the probabilities are that the underlying relative risk may be as high as various possible levels of concern. ${ }^{43}$ The probability is only about $2 \%$ that the underlying relative risk is as high as 1.5 . Similarly, the probabilities are $5 \%, 12 \%$, and $25 \%$ that the relative risk might be as high as $1.4,1 \cdot 3$, or $1 \cdot 2$ respectively. (If the heterogeneity among the relative risks is taken into account, then the probabilities are about $14 \%, 20 \%, 27 \%$, and $35 \%$ that the underlying relative risk might be as high as $1 \cdot 5,1 \cdot 4$, 1.3 or 1.2 , respectively). In summary, the overall tabulation of leukaemia yields small probabilities that the risk from EtO exposure is very large,

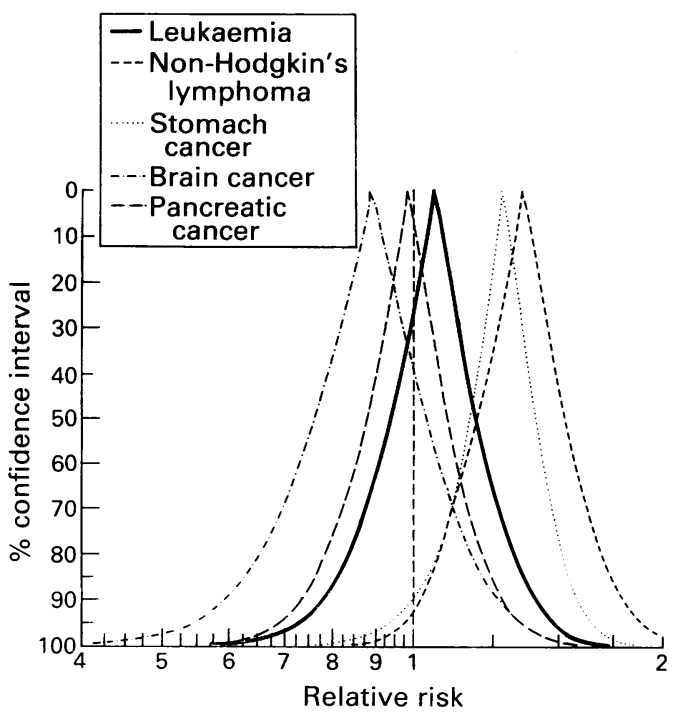

Figure 6 Confidence interval functions ${ }^{42}$ for leukaemia, nonHodgkin's lymphoma, stomach cancer, brain and nervous system cancer and pancreatic cancer, based on the meta-analyses of the combined studies. and the overall data are easily compatible with no risk.

Figure 6 also shows that, for all the endpoints except non-Hodgkin's lymphoma and stomach cancer, a relative risk of one is easily compatible with the data i.e., there is appreciable overlap of the confidence intervals with values of one and below. As discussed, the data for non-Hodgkin's lymphoma are suggestive of an effect, but are inadequate for inferring causality at this time. For stomach cancer the overlap is small, and, at face value, suggests the possibility of an effect. However, the confidence intervals that have been plotted do not take heterogeneity of the effects into account, as arguably they should. If they were to do so, even the CI for stomach cancer would show an appreciable overlap with a relative risk of one and below, i.e., the $95 \%, 90 \%, 75 \%$, and $50 \%$ lower CI for stomach cancer, including heterogeneity, are $0.73,0.79,0.92$, and 1.05 , respectively. In any case, as discussed earlier, the stomach cancer risk does not show gradients with intensity or duration of exposure, so a genuine association does not seem likely.

\section{SUMMARY AND CONCLUSIONS}

The studies range in size from $<200$ exposed workers to $>18000$ (table 1) and total about 29800 exposed workers, of whom 2540 were known to have died. To evaluate cancer risk, it is desirable to have more than 20 years of follow up, especially before a conclusion of "no effect" can be drawn. While several of the studies fulfilled this criterion, a number of them did not, and for others inadequate information was presented to determine the average or distribution of follow up times. The low spontaneous rates of leukaemia, combined with the relatively short follow up times, means that only 29.3 leukaemia cases/deaths were expected. Hence, even a meta-analysis of the combined leukaemia data has rather limited statistical power and precision unless there is a large excess risk, especially when the data are broken into finer subgroupings. Nevertheless, a meta-analysis greatly improves the statistical power as compared with analyses of the individual studies. The limitations 
on statistical power and precision mandate further follow up of these exposed populations in order to reduce uncertainty.

The levels of EtO exposure for the workforces included in these studies are uncertain, since industrial hygiene measurements were not generally made until after the mid-1970s. Inadequate information on individual exposure levels meant that exposure-response analyses were limited or impossible, and that risks could not be calculated per unit dose. The statistical power was also limited because a number of the studies had a large fraction of the cohort with rather low levels of cumulative exposure, resulting from various combinations of short duration and low intensity of exposure. Nevertheless, the cumulative exposure analysis by Stayner $e t a^{15}$ represents a significant advance in the quantitative analysis of EtO effects.

In many of the studies the workers had exposures to a variety of other chemicals besides EtO. Hence, it is possible that certain "positive" findings were in reality caused by some other correlated exposure. This possibility should be kept in mind especially when only one or two studies tended to show a "positive" finding but the others did not.

The levels of EtO exposure in these studies, which often were higher than in industry today, were generally not associated with cancer risks, although the question is unresolved for leukaemia and non-Hodgkin's lymphoma (or non-Hodgkin's lymphoma plus lymphocytic leukaemia). The weight of evidence indicates no association between EtO and other types of cancer. The suggestive but uncertain findings about whether leukaemia and non-Hodgkin's lymphoma are caused by EtO emphasise the pressing need for more data.

\section{Appendix}

CALCULATION OF A TEST OF HETEROGENEITY FOR THE STANDARDISED MORTALITY RATIO (SMR) AND CALCULATION OF A CONFIDENCE INTERVAL FOR THE SMR UNDER THE ASSUMPTION OF HETEROGENEITY The test for heterogeneity of SMRs is an analogue of the test often used to evaluate heterogeneity of the odds ratio across strata. ${ }^{44}$ Let $O_{i}$ be the observed value and $\mathrm{E}_{\mathrm{i}}$ be the expected value for study i. Let $\mu=\left(\Sigma \mathrm{O}_{\mathrm{i}}\right) /\left(\Sigma \mathrm{E}_{\mathrm{i}}\right)$, i.e., the overall SMR across all studies. Then the heterogeneity $\chi^{2}, \mathrm{X}_{\mathrm{h}}{ }^{2}=$ $\Sigma\left(\left(\mathrm{O}_{\mathrm{i}}-\mu \mathrm{E}_{\mathrm{i}}\right)^{2} / \mu \mathrm{E}_{\mathrm{i}}\right)$. This is distributed approximately as $\chi^{2}$ with $\mathrm{n}-1$ degrees of freedom $\left(\mathrm{df}_{\mathrm{h}}\right)$, where $\mathrm{n}=$ the number of studies.

Armitage $^{32}$ has suggested that an approximate method to correct the standard error of an estimate for heterogeneity is to multiply the variance of that estimate by a factor representing the heterogeneity of the studies (or strata) that generated the estimate. In particular, the heterogeneity factor is taken to be the ratio of the heterogeneity $\chi^{2}$ to its degrees of freedom. (This would be applied only when the ratio is $>1$-that is, when the $\chi^{2}$ is greater than its degrees of freedom). To calculate a heterogeneity-adjusted confidence interval using the Armitage method, ${ }^{32}$ we work with the logarithm (log) of the overall SMR because $\log (\mathrm{SMR})$ is an approximate Gaussian variate. The approximate variance $(V)$ of $\log (\mathrm{SMR})$ is the reciprocal of the total observed number-that is, $1 / \Sigma \mathrm{O}_{\mathrm{i}}$. An estimate of the $95 \%$ confidence interval for the SMR is: $\exp \left(\log (S M R)-1.96^{\star} V^{1 / 2}\right)$ to $\exp (\log (S M R)$ $\left.+1.96^{\star} V^{1 / 2}\right)$. To adjust for heterogeneity using Armitage's approximate method, ${ }^{32}$ we multiply the variance $V$ by the ratio of the heterogeneity $\chi^{2}$ to its degrees of freedom-that is, $V^{\mathrm{h}}=V^{\star} \mathrm{X}_{\mathrm{h}}{ }^{2} / \mathrm{df}_{\mathrm{h}}$, and $V^{\mathbf{n}}$ is substituted for $V$ in the formulae for the CI.

Thanks go to Dr M Jane Teta of Union Carbide Corporation and Dr Barbara Divine of Texaco for providing unpublished manuscripts and tabulations to update the database on which this review was based. The assistance of Mrs Miriam Moseson and LaVerne Yee in manuscript preparation is also appreciated.

This study was supported by a contract from th $\bar{Q}$ Chemical Manufacturers Association, Washington DC and by center grants CA13343 and CA1608\% from the National Cancer Institute and ES0026 from the National Institute of Environmental Health Sciences.

Requests for reprints to: Dr Roy Shore, Department of Environmental Medicine, 341 E. 25 St, New York University Medical Center, New York, NY, 10010-2598, USA.

1 Selected Petrochemical Statistics. US trade, production and consumption. National Petroleum Refiners Assoc, 1992; Washington, DC.

2 National Toxicology Program. Toxicology and carcinogenesis studies of ethylene oxide, NTP TR 326. Washington, DC: Government Printing Office (NIH publ No 88-2582), 1987.

3 International Agency for Research on Cancer. Ethylene oxide. IARC Monogr on Eval of Carcinogenic Risk of Chemicals to Humans 1985;36:189-226.

4 Hogstedt C, Malmqvist N, Wadman B. Leukemia in workers exposed to ethylene oxide. ${ }^{\prime} \mathrm{Am}$ Med Assoc 1979;241:1132-3.

5 Hogstedt C, Rohlen O, Berndtsson B, Axelson O, Ehrenberg L. A cohort study of mortality and cancer incidence in ethylene oxide production workers. $\mathrm{Br} F$ Ind $\mathrm{Med} 1979$; 36:276-80.

6 Hogstedt C, Aringer L, Gustavsson A. Epidemiologic support for ethylene oxide as a cancer-causing agent. $7 \mathrm{Am}$ Med Assoc 1986; 255:1575-8.

7 Hogstedt LC. Epidemiologic studies on ethylene oxide and cancer: an updating. IARC Sci Publ 1988;89:265-70.

8 Hagmar L, Welinder $\mathrm{H}$, Linden $\mathrm{K}$, Attewell $\mathrm{R}$, OstermanGolkar S, Tornqvist M. An epidemiological study of cancer risk among workers exposed to ethylene oxide using hemoglobin adducts to validate environmental exposure assess- 
ments. Int Arch Occup Environ Health 1991;63:271-7.

9 Thiess AM, Frentzel-Beyme R, Link R, Stocker W. Mortality study on employees exposed to alkylene oxides (ethylene oxidelpropylene oxide) and their derivatives. Prevention of Occupational Cancer (Occupational Safety and Health Series). Geneva: International Labour Office; 1981;46:249-59.

10 Kiesselbach N, Ulm K, Lange $\mathrm{H}$, Korallus U. A multicentre mortality study of workers exposed to ethylene oxide. $\mathrm{Br} \mathcal{F}$ Ind Med 1990;47:182-8.

11 Morgan RW, Claxton K, Divine B, Kaplan S, Harris V. Mortality among ethylene oxide workers. 7 Occup Med $1981 ; 23: 767-70$.

12 Greenberg HL, Ott M, Shore R. Men assigned to ethylene oxide production or other ethylene oxide related chemical manufacturing: a mortality study. $\mathrm{Br} \mathcal{F}$ Ind $\mathrm{Med}$ 1990:47: 221-30.

13 Teta MJ, Benson L, Vitale J. Mortality study of ethylene oxide workers in chemical manufacturing: a ten-year update. $\mathrm{Br} \mathcal{F}$ Ind Med 1993;50:704-9.

14 Steenland K, Stayner L, Greife A, Halperin W, Hayes R, Hornung R, Nowlin S. Mortality among workers exposed to ethylene oxide. N Engl F Med 1991;324:1402-7.

15 Stayner L, Steenland K, Greife A, Hornung R, Hayes R Nowlin $\mathrm{S}$, et al. Exposure-response analysis of cancer mortality among a cohort of workers exposed to ethylene oxide. Am 7 Epidemiol 1993; (in press).

16 Wong $\mathrm{O}$, Trent L. An epidemiological study of workers potentially exposed to ethylene oxide. $\mathrm{Br} f \mathrm{f}$ Ind $\mathrm{Med}$ 1993;50:308-16.

17 Gardner MJ, Coggon D, Pannett B, Harris E. Workers exposed to ethylene oxide: a follow-up study. $\mathrm{Br} \mathcal{F}$ Ind $\mathrm{Med}$ 1989;46:860-5

18 Bisanti L, Maggini M, Raschetti R, Alegiani S, Ippolito F, Caffari B, Segnan N, Ponti A. Cancer mortality in ethylene oxide workers. Br f Ind Med 1993:50:317-24.

19 WHO. International Classification of Diseases, 8th revision Geneva World Health Organisation, 1967.

20 WHO. International Classification of Diseases, 9th revision. Geneva: World Health Organization, 1977.

21 Doll R. Occupational cancer: problems in interpreting human evidence. Ann Occup Hyg 1984:28:291-305.

22 Rothman KJ. A sobering start for the cluster busters' conference. Am F Epidemiol 1990;132:S6-13.

23 Ehrenberg L, Hallstrom T. Cited by Kalling L. Haematologic studies on persons occupationally exposed to ethylene oxide. Radiosterilization of medical products. (SM 92/96) 1967; Vienna: International Atomic Energy Agency, $327-34$.

24 Golberg L. Hazard assessment of ethylene oxide. CRC Press, Boca Raton, 1986:196.

25 Park RM, Silverstein M, Mirer F. Characteristics of worker populations: exposure considerations in the selection of study populations and their analysis. Applied Occupational and Environmental Hygiene 1991;6:436-40.

26 Joyner RE. Chronic toxicity of ethylene oxide. Arch Environ Health 1964;8:700-10.

27 Benson L, Teta MJ. Mortality due to pancreatic and lymphopoietic cancers in chlorohydrin production workers. $\mathrm{Br} \mathcal{f}$ Ind Med 1992;50:710-6.
28 Greife AL, Hornung R, Stayner L, Steenland K. Development of a model for use in estimating exposure to ethylene oxide in a retrospective cohort mortality study. Scand $\mathcal{F}$ Work Environ Health 1988;14:29-30.

29 Breslow NE, Day N. Statistical methods in cancer research. Vol II-The design and analysis of cohort studies. Oxford Univ Press, New York: 1987;406pp.

30 DerSimonian R, Laird N. Meta-analysis in clinical trials. Controlled Clin Trials 1986;7:177-88.

31 Fleiss JL, Gross A. Meta-analysis in epidemiology, with special reference to studies of the association between exposure to environmental tobacco smoke and lung cancer: a critique. $\mathcal{F}$ Clin Epidemiol 1991;44:127-39.

32 Armitage P. Statistical considerations: conclusion. In: Interpretation of negative epidemiological evidence for carcinogenicity. NJ Wald, R Doll, eds. International Agency for Research on Cancer, Lyon 1985:190 (IARC Publ No 65.)

33 Greenland S. Quantitative methods in the review of epidemiologic literature. Epidemiol Rev 1987;9:1-30.

34 Lancaster HO. Significance tests in discrete distributions. Fournal of the American Statistical Association 1961;56 223-34.

35 Pasternack BS, Shore R. Statistical methods for assessing risk following exposure to environmental carcinogens. In: Environmental health: quantitative methods. Whittemore A ed. Society for Industrial and Applied Mathematics, Philadelphia 1977;48-70.

36 Lagakos SW. Effects of mismodelling and mismeasuring explanatory variables on tests of their association with a response variable. Stat Med 1988;7:257-74.

37 Shore RE, Iyer V, Altshuler B, Pasternack B. Use of human data in quantitative risk assessment of carcinogens: impact on epidemiologic practice and the regulatory process. Regul Toxicol Pharmacol 1992;15:180-221.

38 Muir C, Waterhouse J, Mack T, Powell J, Whelan S. Cancer incidence in five continents. International Agency for Research on Cancer, Lyon 1987; Vol V. (IARC Publ No 88.)

39 Austin SG, Sielken R, Jr. Issues in assessing the carcinogenic hazards of ethylene oxide. F Occup Med 1988;30:236-45.

40 Dunkelberg H. Carcinogenicity of ethylene oxide and 1,2propylene oxide upon intragastric administration to rats. $\mathrm{Br}$ f Cancer 1982;46:924-33.

41 Poole C. Beyond the confidence interval. Am f Pub Health 1987;77:195-9.

42 Sullivan KM, Foster D. Use of the confidence interval function. Epidemiol 1990;1:39-42.

43 Smith AH, Bates $M$. Confidence limit analyses should replace power calculations in the interpretation of epidemiologic studies. Epidemiol 1992;3:449-52.

44 Breslow N, Day N. Statistical methods in cancer research. Vol 1-The analysis of case-control studies. International Agency for Research on Cancer, Lyon 1980.

45 Waterhouse J, Muir C, Correa P, Powell J. Cancer incidence in five continents. IARC Scientific Publication 15, International Agency for Research on Cancer, Lyon, France 1976; Vol. III, 584pp.

46 National Cancer Institute Cancer Statistics Review-1973NIH Publication No 90-2789, Bethesda, MD 1990 